No 2013-03

February

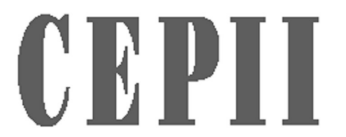

CENTRE

D'ÉTUDES PROSPECTIVES

ET D'INFORMATIONS

INTERNATIONALES

Trend shocks and economic development

Claude Francis Naoussi and Fabien Tripier 


\section{TABLE OF CONTENTS}

Non-technical summary. . . . . . . . . . . . . . . . . . . . . . . . . . . 3

Abstract . . . . . . . . . . . . . . . . . . . . . . . . . . . . . . 4

Résumé non technique . . . . . . . . . . . . . . . . . . . . . . . . . . 5

Résumé court . . . . . . . . . . . . . . . . . . . . . . . . . 6

1. Introduction . . . . . . . . . . . . . . . . . . . . . . . . 7

2. The stylized facts . . . . . . . . . . . . . . . . . . . . . . . . . . . . 10

3. Identifying the sources of fluctuations . . . . . . . . . . . . . . . . . . . . 12

3.1. The model . . . . . . . . . . . . . . . . . . . . . . . . . . . . 12

3.2. The identification strategy . . . . . . . . . . . . . . . . . . . . . . . 14

4. Results . . . . . . . . . . . . . . . . . . . . . . . . . . . . . 14

4.1. Cross-country differences in business cycle moments . . . . . . . . . . . . 14

4.2. The size of the random walk and the determinants of macroeconomic volatility . . 19

4.3. Robustness. . . . . . . . . . . . . . . . . . . . . . . . . . . . . 21

5. Conclusion . . . . . . . . . . . . . . . . . . . . . . . 22

List of working papers released by CEPII . . . . . . . . . . . . . . . . . . . . 42 


\title{
TREND SHOCKS AND ECONOMIC DEVELOPMENT
}

\author{
Claude Francis Naoussi and Fabien Tripier
}

\section{NON-TECHNICAL SUMMARY}

Developing countries, widely-known to be among the poorest of the world, are also among the most unstable economies. The instability of developing economies generates substantial costs that may be measured, directly, through the welfare costs of consumption fluctuations and, indirectly, through the consequences on growth.

The recent literature has attempted to rationalize this instability by introducing additional shocks (related with commodity prices or international aid, for example) into modern business cycle framework based on dynamic and stochastic general equilibrium models. The few studies that do exist have advanced possible explanations for the high output volatility that characterizes the developing economies, but none succeeds in explaining both the high volatility of consumption, which is higher than the volatility of output, and the acyclical behavior of net-exports, which are countercyclical in emerging countries. In this article, following Aguiar and Gopinath (2007), we assess the relevance of trend shocks to explain business cycle specificities of less developed countries. We collect output, consumption, investment, and net exports series for 22 developed countries, 28 emerging countries, and 32 SSA countries, and we estimate the theoretical model to reproduce business cycle facts. Because we produce one estimate for each country, we can study the relationship between economic development and business cycles by comparing a large number of heterogeneous countries.

We first show the strong relationship between economic development and the weight of trend shocks in the fluctuations of productivity measured by the size of the random walk. The size of the random walk is the highest for the SSA countries and the lowest for developed countries, with intermediary values for emerging countries. We then relate our results to the literature on the sources of fluctuations in developing countries. To this end, we compare the cross-country variations in the size of the random walk with the cross-country variations in the usual determinants of fluctuations in developing countries: the mean of real income per capita, the quality of institution, the growth rate of trade openness, the volatility of aid received by countries as a percent of income, the mean of the size of the domestic credit as a percent of GDP, the mean of the inflation rate, and the mean of the size of government spending as a percent of GDP. Each of these variables has been put forward in the literature as a potential determinant of macroeconomic volatility and is indeed significantly correlated with the volatility of output for our data. By studying the correlation between these variables and the size of the random walk, we seek to identify the potential origins of the trend shocks in developing countries. We find that the size of the 
random walk significantly decreases with the level of income, the quality of institutions, and the size of credit market. The results are ambiguous when correlated with government spending. Interestingly, some variables that are significantly correlated with the volatility of output, are not correlated with the size of the random walk. This is the case for the inflation rate, the trend in trade openness, and the volatility of aid received by countries.

\section{Abstract}

This article explores the role of trend shocks in explaining the specificities of business cycles in developing countries using the methodology introduced by Aguiar and Gopinath (2007) ["Emerging Market Business Cycles: The Cycle Is the Trend" Journal of Political Economy 115(1)]. We specify a small open economy model with transitory and trend shocks on productivity to replicate the differences in the business cycle behavior observed between developed, emerging, and Sub-Saharan Africa countries. Our results suggest a strong relationship between the weight of trend shocks in the source of fluctuations and the level of economic development. The weight of trend shocks is $(i)$ higher in Sub-Saharan Africa countries than in emerging and developed countries, (ii) negatively correlated with the level of income, the quality of institutions, and the size of the credit market, and (iii) uncorrelated with the volatility of aid received by countries, the inflation rate, and the trend in trade-openness.

JEL Classification: E32, F41, O55.

Keywords: $\quad$ Business Cycle; Permanent shocks; Growth; Africa; Small open economy 


\title{
CHOCS DE TENDANCE ET DÉVELOPPEMENT ÉCONOMIQUE
}

\author{
Claude Francis Naoussi and Fabien Tripier
}

\section{RÉSUME NON TECHNIQUE}

Les pays en développement sont caractérisés non seulement par de faibles niveaux de richesse, mais aussi par une très grande instabilité macroéconomique qui entraîne de fortes fluctuations de la consommation et ralentit la croissance de long terme. Comprendre l'origine de cette instabilité macroéconomique pourrait permettre d'y remédier et d'améliorer les conditions de vie dans ces économies. La littérature a proposé plusieurs explications telles que les fluctuations des prix des matières premières, les variations de l'aide au développement ou encore les difficultés d'accès de ces économies aux marchés financiers. L'intégration de ces sources d'instabilité dans les modèles théoriques de cycle économique permet effectivement d'expliquer la forte volatilité de la production dans ces pays, mais elle ne suffit pas à expliquer le comportement cyclique des autres variables macroéconomiques essentielles que sont la consommation, l'investissement et les exportations nettes.

Pour mieux expliquer le cycle économique des pays en développement, nous proposons dans cet article de suivre l'approche initialement développée par Aguiar et Gopinath (2007). Dans cette approche, une seule source du cycle économique est considérée : les fluctuations exogènes de la productivité des facteurs. Par contre, ces fluctuations peuvent être le résultat soit de chocs transitoires de productivité, soit de chocs permanents aussi appelés chocs de tendance parce qu'ils affectent la tendance de long terme de l'économie. Dans cette approche, les différences de cycle économique selon que les pays sont en développement, émergents ou développés s'expliquent par un poids différent des chocs transitoires et des chocs de tendance.

Nous montrons la pertinence de cette approche en estimant un modèle théorique de cycle économique distinguant ces deux types de chocs pour un ensemble de 82 pays (22 pays développés, 28 pays émergents et 32 pays d'Afrique sub-saharienne). Nous montrons qu'il existe une forte relation entre le développement économique et la part des chocs de tendance dans les fluctuations de la productivité, mesurée par la taille de la marche aléatoire. La taille de la marche aléatoire est la plus élevée dans les pays d'Afrique sub-saharienne et la plus faible dans les pays développés, avec des valeurs intermédiaires dans les pays émergents. Nous relions ensuite ces résultats à la littérature sur les sources des fluctuations dans les pays en développement en mesurant les corrélations entre la taille de la marche aléatoire et les variables usuellement associées à l'instabilité des pays en développement : le revenu moyen par habitant, la qualité des institutions, l'ouverture commerciale, la volatilité de l'aide au développement, le développement du crédit, le taux d'inflation moyen et la part moyenne des dépenses publiques dans la production. Chacune de 
ces variables a été mise en avant dans la littérature comme un déterminant potentiel de l'instabilité macroéconomique et est effectivement corrélée avec la volatilité de la production. En étudiant la corrélation entre ces variables et la taille de la marche aléatoire, nous cherchons à identifier les origines potentielles des chocs de tendance dans les pays en développement. Nos résultats suggèrent que le poids des chocs de tendance est significativement plus fort quand le niveau de revenu est bas, la qualité des institutions faible, le marché du crédit peu développé. Les résultats sont ambigus concernant la taille du secteur public. Par contre, plusieurs variables significativement corrélées avec la volatilité de la production se révèlent non significativement corrélées avec la taille de la marche aléatoire : l'inflation, la croissance de l'ouverture commerciale et la volatilité de l'aide au développement.

\section{RÉSUMÉ COURT}

Cet article évalue dans quelle mesure les chocs de croissance peuvent expliquer les spécificités du cycle économique dans les pays en développement à partir du cadre méthodologique développé par Aguiar et Gopinath (2007) (2007) [“Emerging Market Business Cycles: The Cycle Is the Trend” Journal of Political Economy 115(1)]. Nous estimons un modèle de petite économie ouverte avec des chocs de productivité transitoires et permanents pour reproduire les différences observées en termes de cycle économique entre les pays développés, émergents et d'Afrique Sub-saharienne. Nos résultats montrent une forte relation entre le poids des chocs de croissance dans la source des fluctuations et le niveau de développement économique. Le poids des chocs de croissance est $(i)$ plus élevé en Afrique Sub-saharienne que dans les pays émergents et développés, (ii) négativement corrélé avec le niveau de revenu, la qualité des institutions et la taille du secteur du crédit, et (iii) non-corrélé avec la volatilité de l'aide reçue, l'inflation et la croissance de l'ouverture commerciale.

Classification JEL : E32, F41, O55.

Mots clés : $\quad$ Cycle d'activité ; Chocs permanents ; Croissance ; Afrique ; Petite économie ouvertes 


\title{
TREND SHOCKS AND ECONOMIC DEVELOPMENT ${ }^{1}$
}

\author{
Claude Francis Naoussi* and Tripier Fabien ${ }^{\dagger}$
}

\section{INTRODUCTION}

Developing countries, widely-known to be among the poorest of the world, are also among the most unstable economies, and these economies have the highest volatilities of output and consumption. This article explores the role of trend shocks in explaining specificities of business cycles in developing countries. Because developing countries are very heterogeneous, we draw distinction between a set of emerging countries, which are middle-income countries, and SubSaharan Africa (SSA) countries, which are low-income countries. To assess the relationship between trend shocks and economic development as a whole, we also consider a set of highincome developed countries.

The instability of developing economies, which has been documented by Rand and Tarp (2002) and Ramey and Ramey (1995), generates substantial costs that may be measured, directly, through the welfare costs of consumption fluctuations, as demonstrated by Pallage and Robe $(2003)^{2}$, and indirectly through the consequences on growth, as discussed in Loayaza et al. (2007). The recent literature attempts to rationalize this instability within the modern business cycle framework based on dynamic and stochastic general equilibrium models ${ }^{3}$. Many studies on this topic have examined emerging countries ${ }^{4}$, but few have looked at $\mathrm{SSA}^{5}$. The few studies

\footnotetext{
${ }^{1}$ We thank the participants at the Theories and Methods in Macroeconomics Conference (Nantes, 2012), Shocks in Developing Countries Dial Conference (Paris, 2011), KOF-ETH-UZH Seminar in International Economic Policy (Zurich, 2011), LEMNA Seminar (Nantes, 2010), EPEE Seminar (Evry, 2010) in particular Olivier Darné, Erwan Gautier, Jerôme Glachant, and Peter Rosenkranz. The usual disclaimers apply. Financial support from the Chair Finance of the University of Nantes Research Foundation is gratefully acknowledged.

*University of Nantes (LEMNA) (claude.naoussi-defounkou @univ-nantes.fr)

†University of Lille 1 (CLERSE) and CEPII (fabien.tripier@cepii.fr)

${ }^{2}$ The excess volatility of consumption explains the high welfare costs of fluctuations computed by Pallage and Rob (2003) for developing countries, which are at least 10 times greater than those in the United-States.

${ }^{3}$ In their precursory contributions, Mendoza (1995) and Kydland and Zarazaga (1997) apply modern business cycle methodology to emerging countries. This approach has also been pursued by Neumeyer and Perri (2005) and Aguiar and Gopinath (2007).

${ }^{4}$ Emerging countries are mainly in Latin America or Asia, but are also in North Africa. Among the SSA countries, only South Africa is generally considered an emerging country. Emerging countries experience both accelerating growth and crisis events.

${ }^{5}$ Mendoza (1995) and Kose (2002) consider the average behavior of a group of developing countries that encompasses middle- and low-income countries, including several SSA countries. In this paper, we employ an alternative approach that differentiates SSA countries from other developing countries.
} 
that do exist have advanced possible explanations for the high output volatility that characterizes these economies, but none succeeds in explaining both the high volatility of consumption, which is higher than the volatility of output, and the acyclical behavior of net-exports, which are countercyclical in emerging countries.

Kose and Riezman (2001) propose a model in which trade shocks account for a large portion of output fluctuations. When these shocks are combined with transitory productivity shocks, however, the model predicts a volatility of consumption that is half that of output and predicts a strongly countercyclical trade balance ${ }^{6}$. Arellano et al. (2009) emphasize the role of shocks to the aid received by countries in explaining the fluctuations in one African country, Ivory Coast. However, this economy is not representative of African business cycles because consumption is as volatile as output in Ivory Coast. In addition, the authors do not discuss the model's implications for the cyclical behavior of net exports. In Özbilgin (2010), transitory productivity shocks are amplified in low-income countries by the limited participation of agents in financial markets. This financial friction increases the relative volatility of consumption compared to output, but it remains below unity. Moreover, this friction reinforces the countercyclical behavior of the trade balance, which is acyclic in low-income countries ${ }^{7}$. The inability of these models to explain the high volatility of consumption should be interpreted with caution because of data limitations that render durable-nondurable decomposition impossible, whereas consumption is nondurable consumption in most business cycle models. To address this issue, Alvarez-Parra et al. (2011) study countries where data permit such decomposition. They show that the relative volatility of nondurable consumption to output varies among emerging countries (for example, it is 0.89 for Mexico and 1.20 for Chile), but on average nondurable consumption is not more volatile than output ${ }^{8}$. Because data for SSA countries prohibit such decomposition, we use aggregate consumption as usually done in the literature but keeping in mind this limit. Ultimately, the existing literature fails to provide a convincing explanation of why net exports are acyclic in SSA countries. For emerging countries, Aguiar and Gopinath (2007) explain the excess volatility of consumption and the countercyclical behavior of net exports by substantial volatility in the trend growth of labor productivity in these countries. In this article, we assess the relevance of trend shocks to explain business cycle specificities of less developed countries, namely, the SSA countries 9 .

\footnotetext{
${ }^{6}$ More precisely, the relative volatility of consumption is 2.02 for the data against 1.01 for the model, and the correlation of the trade balance with output is -0.10 for the data against -0.72 for the model; see Table 5 (a) of Kose and Riezman (2001).

${ }^{7}$ Özbilgin (2010) matches the coefficient of correlation between net exports and output observed in average for all developing countries. It is negative (and equal to -0.20) and contrary to its value for the low-income developing countries (equal to 0.01) as indicated in Table 1 of Özbilgin (2010).

${ }^{8}$ Alvarez-Parra et al. (2011) report a ratio of volatility equal to 0.90 for a set of five emerging countries and equal to 0.72 for a set of six small developed economies.

${ }^{9}$ With the exception of Houssa et al. (2010), the applications of business cycle models to the SSA countries cited here do not consider permanent shocks. Houssa et al. (2010) estimate a medium-scale business cycle model for the Ghanaian economy with permanent technological shocks, which appears to be the most important source of fluctuations. However, Houssa et al. (2010) do not study the model's predictions for consumption.
} 
Aguiar and Gopinath (2007) consider a real business cycle model for small open economies in the spirit of Mendoza (1991) by examining the impact of two technological shocks on the technology used in the production of goods. The first is a purely transitory shock on the level of total factor productivity, whereas the second is a trend shock on the growth rate of labor productivity at the origin of the stochastic trend in the economy. Aguiar and Gopinath (2007) estimate the structural parameters necessary to reproduce key moments in the business cycles of two countries, Mexico and Canada, which exemplify emerging and developed countries, respectively. They subsequently explain the specificities of the emerging market business cycle by a higher relative weight of the trend shock (or the stochastic trend) when compared with the transitory shock, and they therefore conclude that "the cycle is the trend".

We extend the work of Aguiar and Gopinath (2007) to include SSA countries. Aguiar and Gopinath (2007) succeed in collecting quarterly data for 26 countries (13 emerging and 13 developed). Unfortunately, quarterly data are not available for a large sample of SSA economies over a long sample period ${ }^{10}$. Therefore, we have used the annual data for a relatively long sample period provided by the World Bank macroeconomic databases. We have collected output, consumption, investment, and net exports series for 22 developed countries, 28 emerging countries, and 32 SSA countries (starting in 1960 for most countries and continuing until 2006 in our sample), and we have taken a set of eleven moments to characterize business cycles (mainly standard deviations, correlation with output, and autocorrelation of variables). The following five structural parameters of the model are estimated with GMM methods to match the business cycle facts: the standard deviations of the two shocks, the persistence of trend shocks, the size of capital adjustment costs, and the average long-run growth rate. Because we produce one estimate for each country, we can study the relationship between economic development and business cycles by comparing a large number of heterogeneous countries.

First, we generalize the conclusion of Aguiar and Gopinath (2007) for emerging countries to low-income countries as follows: there is a strong relationship between economic development and the weight of trend shocks in the fluctuations of productivity measured by the size of the random walk. Aguiar and Gopinath (2007) conclude that the size of the random walk is greater for emerging countries than for developed countries. We show that this size is even greater for the SSA countries. When compared with developed countries, the key specificity of emerging countries is the higher standard deviation of trend shocks relative to transitory shocks, which makes consumption more volatile than output and makes net exports countercyclical. To make consumption as volatile as observed in SSA countries, we could again increase the relative standard deviation of trend shocks to transitory shocks. However, it would reinforce the countercyclical behavior of net exports whereas they are rather acyclical in the data for these countries. At this point, the persistence of trend shocks is crucial to make the model consistent with data. A slightly positive persistence of trend shocks in SSA countries, which are negatively autocorrelated in emerging and developed countries, results in the simultaneous occurrence of

\footnotetext{
${ }^{10}$ Peiris and Saxegaard (2007) and Houssa et al. (2010) use quarterly data for Mozambique from 1996-2005 and for Ghana from 1983-1997, respectively.
} 
a high relative volatility of consumption and acyclical net exports.

We then relate our results to the literature on the sources of fluctuations in developing countries ${ }^{11}$. To this end, we compare the cross-country variations in the size of the random walk with the cross-country variations in the usual determinants of fluctuations in developing countries. Seven variables are considered, and they are the following: the mean of real income per capita, the quality of institution, the growth rate of trade openness, the volatility of aid received by countries as a percent of income, the mean of the size of the domestic credit as a percent of GDP, the mean of the inflation rate, and the mean of the size of government spending as a percent of GDP. Each of these variables has been put forward in the literature as a potential determinant of macroeconomic volatility and is indeed significantly correlated with the volatility of output for our data. By studying the correlation between these variables and the size of the random walk, we seek to identify the potential origins of the trend shocks in developing countries. We find that the size of the random walk significantly decreases with the level of income, the quality of institutions, and the size of credit market. The results are ambiguous when correlated with government spending. Interestingly, some variables that are significantly correlated with the volatility of output, are not correlated with the size of the random walk. This is the case for the inflation rate, the trend in trade openness, and the volatility of aid received by countries.

The remainder of the paper is structured as follows. Section 2 presents the key empirical facts, and the model is presented in Section 3. Section 4 discusses the results. Section 5 concludes the paper.

\section{THE STYLIZED FACTS}

In this section, we present our database and the links between economic development and business cycles. The database is described in the Data Appendix, and includes 82 countries, that includes developed $^{12}$ (22), emerging (28), and SSA countries (32). We exclude South-Africa from the SSA countries because it is generally considered an emerging country. The data used

\footnotetext{
${ }^{11}$ Raddatz (2007) and Ahmed and Suardi (2009) provide empirical studies that are not based on business cycle models, that are on the sources of fluctuations in developing countries, and that focus on SSA. Raddatz (2007) considers external shocks in relation to the international economy and natural disasters, and Ahmed and Suardi (2009) examine the role of trade and financial liberalization in creating fluctuations.

${ }^{12} \mathrm{We}$ do not include the United-States in our database because this large country could not be modeled as a small open economy. However, our database includes the following six large economies: Japan, Germany, UK, France, Italy, and Canada, all of which are part of the G7 group. The sample of developed countries of Aguiar and Gopinath (2007) encompasses the Canada and other developed countries are smaller than these large economies. We choose to include these countries in our sample to get a sizeable set of developed countries, as has already been done in the literature; see, for example, Kollmann (2001) for an application of the small open economy model to Japan, Germany, and United Kingdom, and Monacelli (2004) for an application to several OECD countries, including Canada, France, Italy, Japan, United Kingdom, and West Germany.
} 
to compute the business cycle moments are the real consumption ${ }^{13}$ per capita $(C)$, the real investment per capita $(I)$, the ratio of net exports to output $(N X / Y)$, the real GDP per capita in local currency units $(Y)$, and the growth rate $(D Y)$. To compare income across countries, we use the real GDP per capita in constant USD $\left(Y^{*}\right)$ and refer to this variable as "income" in the remainder of the paper. We consider eleven moments to describe the data collected in the vector $m$

$$
m=\left(\begin{array}{c}
\sigma(y) \\
\sigma(D Y) \\
\sigma(c) \\
\sigma(i) \\
\sigma\left(\frac{n x}{y}\right) \\
\rho\left(y, y_{-1}\right) \\
\rho\left(D Y, D Y_{-1}\right) \\
\rho\left(y, \frac{n x}{y}\right) \\
\rho(y, c) \\
\rho(y, i) \\
E(D Y)
\end{array}\right)
$$

where $z$ is the cyclical component of $\log (Z)$ using the HP filter (with a coefficient equal to 100), $\sigma(z)$ denotes the standard deviation of the series $z, \rho(y, z)$ is the correlation coefficient between output $y$ and the variable $z$, for $z=\{y, i, c, n x / y\}$, and $E(D Y)$ is the mean of the growth rate of output $D Y=\log \left(Y / Y_{-1}\right)$.

Table 1 provides the GMM estimates of moments for each group of countries. Figure 1 depicts the relationship between each of the eleven business cycle moments and income (solid lines are the outcome of a linear regression with a slope significantly different from zero at the $1 \%$ level, dashed lines at the 5\% level, and dotted lines at the 10\% level). Each moment is significantly correlated with mean income.

Economic development is positively related to growth ${ }^{14}$ and negatively related to volatility. The standard deviations of the output and of the output growth of SSA countries are twice as great as that of developed countries and are significantly negatively correlated with income. Business cycles are less volatile in developed countries, but are more persistent; the first-order coefficients of autocorrelation of output and output growth are significantly positively correlated with income.

\footnotetext{
${ }^{13}$ The data do not allow us to make the distinction between durable and non-durables goods. Alvarez-Parra et al. (2011) discuss the implications of this distinction for emerging and developed countries, but not for SSA or low-income countries. Restrepo-Echavarria (2011) studies the implications of the informal sector, and its mismeasurement on business cycle facts for consumption in developed countries.

${ }^{14}$ Income is not initial income, as is usually considered when studying convergence issues, but is instead the average of income over the sample. Our data indicate that the average income is higher in economies with a high growth than in other countries.
} 
The increase in the standard deviations of consumption and investment with low development are stronger than for output. Therefore, the relative volatilities of consumption and investment to output decrease with economic development. The ratio of the relative standard deviations of consumption (investment) to output is approximately 1.03 (3.12) for developed countries, 1.22 (3.42) for emerging countries, and 1.80 (4.13) for SSA countries. These ratios of relative standard deviations are significantly negatively correlated with output at the $1 \%$ level for consumption and at the $10 \%$ level for investment (see Figure 1). If excessive consumption volatility is widely known to characterize developing countries, then our data suggest that this volatility is much more pronounced in SSA countries. Interestingly, our data also show a relationship between economic development and the correlation of consumption and investment with output, as already noted by Özbilgin (2010). Consumption and investment are procyclical in all countries, but the coefficient of contemporaneous correlation varies significantly according to the level of income (see Figure 1). These coefficients are equal to 0.78 and 0.83 in developed countries, for consumption and investment, respectively, but only 0.52 and 0.36 , respectively, for SSA countries.

The moments associated with the ratio of net export to output are also significantly correlated with income. Net exports are highly volatile and acyclical in low-income countries, whereas they are less volatile and countercyclical in middle and high income countries. On average, the correlation coefficients between output and net exports are roughly the same for emerging and developed countries at -0.36 and -0.35 , respectively, compared to 0.004 for SSA countries. This point contrasts with Aguiar and Gopinath (2007) who put forward the more pronounced countercyclical behavior of net exports of emerging countries as a key characteristic of these countries. However, Aguiar and Gopinath (2007) note that when they consider annual data for a longer time period, the excess volatility of consumption is a constant characteristic of emerging countries and that this contrasts with the strongly countercyclical behavior of the trade balance.

These stylized facts are consistent with the empirical facts described in earlier involving SSA countries such as Ramey and Ramey (1995), Kose and Riezman (2001), Rand and Tarp (2002), Loayaza et al. (2007), and Özbilgin (2010), even if there may be some secondary divergences due to dataset differences. We propose to use these facts to identify the sources of fluctuations for the countries of our database.

\section{IDENTIFYING THE SOURCES OF FLUCTUATIONS}

This section first presents the model (Section 3.1) and then the strategy used to identify the sources of fluctuations (Section 3.2).

\subsection{The model}

This section summarizes the model of Aguiar and Gopinath (2007) that is a real business cycle model for small open economies in the spirit of Mendoza (1991). The model is purely real with 
two shocks on the final good production technology. The authors emphasize that various sources of disturbances and frictions may be at the origin of these shocks that have to be interpreted broadly as the efficiency wedge following the definition of Chari et al. (2007). The equations are taken from Aguiar and Gopinath (2007) using the same notation.

The final good $Y_{t}$ is produced with two inputs, physical capital $K_{t}$ and labor $L_{t}$, according to a Cobb-Douglas technology

$$
Y_{t}=e^{z_{t}} K_{t}^{1-\alpha}\left(\Gamma_{t} L_{t}\right)^{\alpha}, \text { with } 0<\alpha<1
$$

where $z_{t}$ is the transitory shock on the total factor productivity and $\Gamma_{t}$ the stochastic productivity specific to labor, given by $\Gamma_{t}=e^{g_{t}} \Gamma_{t-1}$ where $g_{t}$ is the trend shock. The two shocks are driven by auto-regressive processes

$$
z_{t}=\rho_{z} z_{t-1}+\varepsilon_{z}, \text { with }\left|\rho_{z}\right|<1 \text { and } \varepsilon_{z} \sim \operatorname{iid}\left(0, \sigma_{z}\right)
$$

and

$$
g_{t}=\rho_{g} g_{t-1}+\left(1-\rho_{g}\right) \mu_{g}+\varepsilon_{g}, \text { with }\left|\rho_{g}\right|<1 \text { and } \varepsilon_{g} \sim \operatorname{iid}\left(0, \sigma_{g}\right)
$$

$e^{z_{t}} \Gamma_{t}^{\alpha}$ correspond to the Solow Residual, which will hereafter be called the "efficiency wedge", as described in Chari et al. (2007).

The representative household maximizes the present sum of discounted values of utility

$$
\sum_{t=0}^{\infty} \beta^{t}\left[\frac{C_{t}^{\gamma}\left(1-L_{t}\right)^{1-\gamma}}{1-\sigma}\right]^{1-\sigma}, \text { with } 0<\gamma<1 \text { and } \sigma>0
$$

where $C_{t}$ is consumption, $\left(1-L_{t}\right)$ is leisure time, and $(\sigma, \gamma, \beta)$ are structural parameters of household preferences. The per-period budget constraint of households is

$$
C_{t}+K_{t+1}=Y_{t}+(1-\delta) K_{t}-\frac{\phi}{2}\left(\frac{K_{t+1}}{K_{t}}-e^{\mu_{g}}\right)^{2} K_{t}-B_{t}+q_{t} B_{t+1}
$$

Resources consist of domestic production and debts, and these are allocated to private consumption and investment in physical capital. The accumulation of physical capital is subject to capital depreciation, at the rate $\delta$. Quadratic adjustment costs are weighted by $\phi . B_{t}$, is the level of debt due as of time $t$, and $q_{t+1}$ is the price of debt for the period $t+1$. The representative household maximizes (5) subject to (6).

The model is closed by an upward-sloping supply of loans (not internalized by the representative households) that links the price of debt to the debt level (divided by the stochastic trend)

$$
\frac{1}{q_{t}}=1+r^{*}+\psi\left[\exp \left(\frac{B_{t+1}}{\Gamma_{t}}-b\right)-1\right] \text {, with } \psi>0
$$

where $r^{*}$ is the world interest rate, $b$ is the steady-state level of debt, and $\psi$ determines the sensitivity of the debt price to the deviation of debt with respect to its steady-state level. Finally, given the resource constraint of the small open economy, net exports (also called the trade balance) are equal to the changes in indebtedness (including debt interest): $N X_{t}=B_{t}-q_{t} B_{t+1}$. 


\subsection{The identification strategy}

The identification strategy is based on second-order moments generated by the model computed using the Matlab programs of Aguiar and Gopinath (2007) ${ }^{15}$ and Uhlig (1997). Like Aguiar and Gopinath (2007), we use GMM methods to estimate a set of structural parameters to account for the differences of business cycle moments across countries, which are described by the eleven moments of $m$ in Equation (1). The GMM package of Burnside (1999) is used to implement the GMM estimation of the moments for the data and of the structural model.

Our strategy is close to the "Method 4" of Aguiar and Gopinath (2007, Table 4 p. 91), except that we fix the value of $\rho_{z}$ whereas they estimate its value. We explain in Section 4.3 that this choice allows us to obtain more accurate estimations and we present the results when this parameter is estimated to show the robustness of our conclusions. Therefore, we estimate ${ }^{16}$ the volatilities of transitory and trend shocks ( $\sigma_{z}$ and $\sigma_{g}$, respectively), the persistence of trend shocks $\left(\rho_{g}\right)$, the size of adjustment costs $(\phi)$, and the long run growth rate $\left(\mu_{g}\right)$. Other parameters are set according to the benchmark parameter values of Aguiar and Gopinath (2007, Table 3 p.86): $\beta=1 /\left(1.02^{4}\right), \gamma=0.36, b=0.10, \psi=0.001, \alpha=0.68, \sigma=2, \delta=\left(1.05^{4}-1\right)$, and $\rho_{z}=$ $0.95^{4}$.

\section{RESUlts}

This section presents our results and is organized as follows. In Section 4.1, we demonstrate the ability of the small open economy model to explain international differences in business cycle moments. We show that this explanation implies strong international differences in the size of the random walk. Then, in section 4.2, we study the relationship between the size of the random walk and the usual determinants of macroeconomic volatility in developing countries. The robustness of our conclusion is assessed in Section 4.3.

\subsection{Cross-country differences in business cycle moments}

Tables 1 and 3 give the outcome of the GMM estimations, respectively, for the moments and the parameters, by taking the average for each type of country (developed, emerging, and SSA). Observed and predicted moments for three selected ${ }^{17}$ countries are given in Tables 2 using the parameter values given in Table 3. The Figure 2 shows the impact of the structure of shocks on the key moments, and the Figure 3 compares the predicted moments by the model with those observed in the data.

\footnotetext{
${ }^{15}$ The programs are adapted for annual data.

${ }^{16}$ The function quadmin.m of the GMM package Burnside (1999) is replaced by the function of matlab fmincon.m to allow for constraints on parameter values in the estimation process. Let us denote $\eta=\left(\sigma_{g}, \sigma_{z}, \rho_{g}, \mu_{g}, \phi\right)$ the vector of estimated parameter, which lower and upper bounds are $(0,0,-.99, .9,0)$ and $(\infty, \infty, .99,1.2,15)$. The GMM estimation is launched for the following initial values $\left(0.01,0.01,0.01,1.006^{\wedge} 4,4\right)$.

${ }^{17}$ Supplementary materials for the full tables of moments and parameters for all countries are available upon request.
} 


\subsubsection{Parameters}

The parameter $\mu_{g}$ adjusts to match the 11th moments of $m$, see Equation (1), that is, the mean of output growth, which is well reproduced, as shown in the Figure 3 (see the last cell where $E(D Y)=\mu_{g}-1$ ). This parameter is below 0.98 for some SSA countries (Democratic Republic of the Congo, Madagascar, and Togo) and above 1.05 in several emerging countries (Korea, China, and Thailand). The average value of $\mu_{g}$ is slightly higher in emerging (1.0247) than in developed countries (1.0235) and notably lower in SSA countries (1.0068). The estimates for the parameter $\phi$ ranges from $3^{-9}$ for Egypt to 2.06 for Mozambique, and these show larger variations between SSA countries (from $6^{-9}$ to 2.006) and between emerging countries (from $3^{-9}$ to 1.839 ) than between developed countries (from 0.002 to 0.44 ). The average values by type of countries is therefore roughly similar $(0.22,0.30$, and 0.26 for developed, emerging, and SSA countries, respectively $)^{18}$.

The estimates for the parameter $\sigma_{z}$ show large variations between countries without significant difference between types of countries. Values close to zero, approximately $1^{-5}$, are estimated for developed, emerging, and SSA countries (such as Denmark, Chile, and Ivory Coast). The maximum value for SSA countries is $3.76 \%$ (Rwanda), this figure is not too far of emerging countries (3.46\% for Iran) but notably higher than the maximum for developed countries $(1.70 \%$ for Luxembourg). The mean value of $\sigma_{z}$ for SSA countries $(0.58 \%)$ is smaller than the mean values in developed $(0.68 \%)$ and in emerging countries $(0.73 \%)$. Because the persistence of transitory shocks is equal for all countries $\left(\rho_{z}=0.95^{4}\right)$, this implies that the high volatility of SSA countries is explained by trend shocks.

The variance of trend shocks is determined by two parameters, $\sigma_{g}$ and $\rho_{g}$, by the following expression $\operatorname{VAR}\left(g_{t}\right)=\sigma_{g}^{2} /\left(1-\rho_{g}^{2}\right)$, given the process defined by Equation (4). On average, the autocorrelation is weak, slightly positive for SSA countries (equal to 0.05) and negative for developed and emerging countries (equal to -0.13 and -0.11 , respectively). Variations in the estimates for $\sigma_{g}$ are more important. The average of $\sigma_{g}$ value for SSA countries is $6.20 \%$, twice that of developed countries $(2.89 \%)$ and above that for emerging countries $(5.33 \%)$. These estimates for $\sigma_{g}$ and $\rho_{g}$ induce marked differences in $\operatorname{VAR}\left(g_{t}\right)$, which reaches its maximum of 0.0144 in Rwanda (a SSA country) and reaches its minimum of 0.0002 in Luxembourg (a developed country). On average, the variance of the stochastic trend is 0.09651 in developed countries, 0.348 in emerging countries, and 0.489 in SSA countries.

The main difference between emerging and developed countries is the relative size of the standard deviations of shocks. Aguiar and Gopinath (2007) explain that the signs of the responses

\footnotetext{
${ }^{18} \mathrm{It}$ is worth mentioning that the estimate for the capital adjustment cost parameter is smaller in Mexico than in Canada, contrary to the results reported by Aguiar and Gopinath (2007). This result is rather counter-intuitive in that it makes capital adjustment costs higher in a developed than in an emerging country. It may be because the estimation procedure forces the model to match the high investment volatility in Mexico by imposing low adjustment costs. Nevertheless, when average values are considered, the lowest estimated value for this parameter is for developed countries and not for emerging or SSA countries.
} 
of relative consumption and relative net exports are different between a transitory shock and a trend shock. A positive transitory (trend) shock induces a negative (positive) response of the ratio of consumption to output and a positive (negative) response of the ratio of net exports. These properties are attributable to the role of permanent income in the general equilibrium model of business cycle ${ }^{19}$. Figure 2 illustrates the key differences between countries.

The top of the Figure 2 reports four key moments for various values of the ratio of standard deviation of shocks $\sigma_{g} / \sigma_{z}$. The solid lines are for the values of moments when the average estimates for developed countries are used (that is the first column of Table 3), except for $\sigma_{g}$, which varies between $0.001 \times \sigma_{z}$ and $15 \times \sigma_{z}$ ). The dotted lines report the values of moments using the same parameter values except for the persistence parameter $\rho_{g}$, and this is set to its average value for SSA countries (see the third column in Table 3). We then report the moments associated with these estimates of structural parameters ${ }^{20}$. The circle marks represent the developed countries and are by construction on the solid lines. Interestingly, the diamond marks, which are for emerging countries, are close to the solid lines but to the right of the circle marks. Emerging countries look like developed countries with more volatile innovations in the trend shocks. The star marks for SSA countries are at the right of both the circle and the diamond marks but far from the solid lines. If the solid and dotted lines are close for the relative volatility of consumption, it is not the case for other moments. The difference in persistence explain why, even if the relative standard deviation of trend shocks is higher in SSA countries than in emerging and developed countries, the consumption is less correlated with output, the relative volatility of net exports is higher, and net exports are less countercyclical in these countries.

The bottom of the Figure 2 is constructed similarly for three specific countries (and not an average of countries): a developed country (Canada), an emerging country (Mexico), and a SSA country (Lesotho). For Canada and Mexico, the picture is similar to that described by Aguiar and Gopinath (2007) for these two countries. The higher volatility of trend shocks explains why consumption is more volatile than output in Mexico (and not in Canada) and why net exports are countercyclical in Mexico (and not in Canada). The difference in the standard deviation of shocks, however, does not explain the difference in business moments between Canada and Lesotho. It is the positive persistence of trend shocks in Lesotho that explains the joint behavior of net exports (highly volatile and procyclical) and consumption (more volatile than output with a middle procyclical behavior).

\footnotetext{
${ }^{19}$ Trend shocks have permanent effects on income in contrast to transitory shocks and therefore induce a response of consumption that is stronger than that of output. In response to a positive trend shock, households increase their propensity to consume, whereas they increase their propensity to invest in response to a transitory shock (to take advantage of temporary improvement in the marginal productivity of capital).

${ }^{20}$ The corresponding numbers may differ from the numbers reported in Table 1, in which the average of predicted moments and not the predicted moments for the average values of parameter estimates as is reported in Figure 2.
} 


\subsubsection{The size of the random walk}

To summarize these strong differences in the structure of parameter of shocks, we compute the size of the random walk (RWS) to measure the contribution of trend shocks to the overall fluctuations of TFP, defined as follows by Aguiar and Gopinath (2007)

$$
\mathrm{RWS}=\frac{\sigma_{\Delta \tau}^{2}}{\sigma_{\Delta_{S R}}^{2}}=\frac{\alpha^{2} \sigma_{g}^{2} /\left(1-\rho_{g}\right)^{2}}{\left[2 /\left(1+\rho_{z}\right)\right] \sigma_{z}^{2}+\left[\alpha^{2} \sigma_{g}^{2} /\left(1-\rho_{g}^{2}\right)\right]}
$$

where $\sigma_{\Delta_{S R}}^{2}$ is the variance of the Solow Residual (defined by $S R_{t}=z_{t}+\alpha \log \Gamma_{t}$ ) and $\sigma_{\Delta \tau}^{2}$ is the variance of the random walk component of $S R_{t}$. Aguiar and Gopinath (2007) find that the random walk size is greater in Mexico (equal to 1.13) than in Canada (equal to 0.38) (see column 4 of Table 4 p. 91). We also obtain sizeable differences between groups: the random walk size is equal to 0.65 for developed countries, 0.76 for emerging countries, and 1.24 for SSA countries. These average values hide strong variability between countries and within a group of countries. For example, the lowest value of random walk size in SSA is 0.27 for Rwanda, which is much lower than the maximum value of random walk size in developed countries: 1.24 for Norway. For emerging countries, the values of the random walk size range between 0.36 (for India) and 1.76 (for Algeria). If we consider the $20 \%$ of countries with the highest values of random walk size, we find only 1 developed, 3 emerging, and 12 SSA countries. In contrast, among the $20 \%$ of countries with the lowest values of random walk size, we find 9 developed, 4 emerging, and 3 SSA countries.

We test the equality of RWS between each possible pair of two countries ${ }^{21}$. For $81.99 \%$ of the 3321 pairs of countries ${ }^{22}$, the probability of being wrong while rejecting the null hypothesis that the two RWS are equal is less than 5\%. Thus, the reported differences in RWS are significantly different from zero for most countries considered here. Considering only countries of the same type does not modify this conclusion. The probability of being wrong while rejecting the null hypothesis is less than $5 \%$ for $78.35 \%$ of developing countries, $82.80 \%$ of emerging countries, and $76.81 \%$ of SSA countries. On this point, SSA countries are the most homogeneous because almost $25 \%$ of pairs do not show significantly different RWS values (at the $5 \%$ level), whereas emerging countries are the most heterogeneous, with only $18 \%$ of pairs that not show significantly different RWS (at the 5\% level). We discuss below how these differences in the estimates of the RWS can be rationalized. Before we do this, we confront the model's predictions with data.

\subsubsection{Moments}

We first consider the ability of the model to reproduce the moments in average, see Table 1 . The volatilities of cyclical output and output growth are reproduced remarkably well by the model.

\footnotetext{
${ }^{21}$ Standard errors are computed by Monte Carlo simulations (with $10^{6}$ realizations) using the calibrated values for $\alpha$ and $\rho_{z}$ and the estimated values for the mean and the standard error of $\sigma_{z}, \sigma_{g}$, and $\rho_{g}$.

${ }^{22}$ Given our sample of 82 countries, we get 3321 pairs of countries.
} 
Indeed, the most sizeable gap between the model and the data is for the standard deviation of output in SSA countries, and this gap is modest (5.16 for the model compared to 4.25 for the data). However, the persistence of cyclical output for the three types of countries and of output growth for SSA countries is overestimated by the model (the auto-correlation of output growth in SSA is equal to 0.44 for the model compared to 0.13 for the data). The model overestimates the correlation of consumption with output for three types of countries. Even if it predicts that the lowest value of this correlation is for SSA countries $(0.80)$, it is above the mean value observed (0.52). The volatilities of consumption relative to the volatility of output are close to the empirical counterparts for developed countries ( 0.95 for the model compared to 1.04 for the data) and emerging countries (1.03 compared to 1.22), but is markedly underestimated for SSA countries (1.05 compared to 1.76). The model predictions are closer to the observed moments for the two other series: investment and net-export. For SSA countries, the model succeeds in predicting the low correlation of investment with output ( 0.43 against 0.36 in the data), the acyclical behavior of net export ( 0.01 against 0.00 in the data), the high relative volatilities of investment (3.23 against 4.13 in the data) and of net export (1.15 compared to 1.19 in the data).

To provide an overall view of the fit of the model, Figure 3 reports the following values for each moment and country: the predicted value by the model, the value for the data, and the value for the data more or less two times its standard deviation. To simplify the reading of the figure, for each subplot, data are sorted in increasing order with respect to the value for the data. This figure confirms the conclusion reached above based on the average values. Except for a reduced number of countries, the model predictions for the standard deviations of cyclical output and output growth are within the empirical ranges. The predicted and observed values for the standard deviation of investment are very close, whereas for consumption, the solid line for the model is generally below the dashed line for the data, especially when consumption is highly volatile. For the ratio of net exports to output, the model overestimates the low values of its standard deviation and matches better its middle and high values. A similar pattern is observed for output persistence. The low values of the first order autocorrelation coefficients of cyclical output and output growth are overestimated, but the middle and high values are closer. Finally, the correlation with output of investment is better reproduced than its correlation with consumption.

To decide whether the model is consistent overall with data, we compute the statistics $Q$ and the associated $p$-values embedded in the GMM package of Burnside (1999). The lowest $p$-value is 0.30 for Uruguay; the probability of being wrong while rejecting the null hypothesis that moments are equal for the model and the data is $30 \%$. For all other countries, the $p$-values are higher and have the following mean values: 0.54 for developed countries, 0.56 for emerging countries, and 0.63 for SSA countries. Based on these figures, we conclude that the small open economy model provides a satisfying description of the international differences in business cycle moments. Next, we discuss the relationship between the relative weight of trend shocks and the determinants of macroeconomic volatility. 


\subsection{The size of the random walk and the determinants of macroeconomic volatility}

Our results suggest that the structure of shocks is the key determinant of the specificities of business cycles in developing countries. Trend shocks should not be interpreted only in terms of variations in technological progress in the economy. According to Aguiar and Gopinath (2007), trend shocks to the efficiency wedge can be associated with regime switches or changes in government policy, including dramatic changes in fiscal, monetary, and trade policies ${ }^{23}$. Trend shocks can also be interpreted as long-term changes in market frictions because they impact the efficiency wedge, as demonstrated by Chari et al. (2007) for financial frictions and by Lagos (2006) for labor market frictions.

To obtain more information on the sources of trend shocks, we compare cross-country variations in the size of the random walk with cross-country variations of the following determinants of macroeconomic volatility in developing countries: $(i)$ the mean of real income per capita, $(i i)$ the quality of the institution, (iii) the growth rate of trade openness, (iv) the volatility of aid received by countries as a percent of income, $(v)$ the mean of the size of the domestic credit as a percent of GDP, $(v i)$ the mean of the inflation rate, and (vii) the mean of the size of government spending as a percent of GDP. Corresponding series are defined in the Data Appendix. For each variable, we measure its correlation with both the standard deviation of output and the size of the random walk. The results are reported in Figures 4 and 5, which, respectively, provide the scatter plots and the line of regression if the slope is significantly different from 0 at the $1 \%$ level (with a solid line), at the 5\% level (with a dashed line), or at the $10 \%$ level (with a dotted line). We do not plot the regression line at other levels.

At the $1 \%$ level, income is significantly negatively correlated with both output volatility and the size of the random walk. This property is consistent with our results reported in the Section 4 because the average of income is highest for developed countries and lowest for SSA countries, and emerging countries are mainly middle-income. To illustrate this property, we compare the gap in income between two countries and the probability that these two countries have different sizes of random walks. The gap in income is defined as $\left|y_{i}^{*}-y_{j}^{*}\right|$ where $y_{z}^{*}$ is the average of the income per capita in country $z$ in real USD of 2000 for $z=i, j$ and $i \neq j$. The mean of this gap is approximately 1.92 for our complete sample of 82 countries. If we consider the pairs of countries for which the gap in random walk size is significantly different from zero (at the 5\% level) the mean of the output gap increases to 1.96. If we consider the countries for which it is not significantly different from zero, the output gap falls to 1.73 . In other words, the gap in income is smaller between countries with similar sizes of random walk.

The quality of institutions is significantly negatively correlated (at the $1 \%$ level) with both output volatility and the size of the random walk. The quality of institutions has been widely recognized as a key determinant of income, growth and, more recently, as a key determinant of

\footnotetext{
${ }^{23}$ In the context of the great depression, Crucini and Kahn (2003) demonstrate that tariff shifts in a multi-sectoral model correspond to changes in the efficiency wedge in a mono-sectoral model, as that considered here.
} 
macroeconomic volatility (see the works of Acemoglu et al. (2001) on growth and Acemoglu et al. (2003) on macroeconomic instability). Our results complete this literature by linking the institutions not only to output volatility but also to the contribution of trend shocks to macroeconomic fluctuations, and our results support the interpretation of these shocks given by Aguiar and Gopinath (2007) in terms of government failures (see the beginning of this section). To be more explicit regarding economic policy, we consider the following two variables that capture cross-country variations in monetary and fiscal policy: inflation and government spending. These two variables are strongly correlated with output volatility. In highly volatile countries, inflation is strong and the government sector is small. However, these variables are not linked with the size of the random walk and therefore do not explain the high weight of trend shocks in the developing countries.

For the standard deviation of aid received (measured as a share of income), we exclude the developed countries from the analysis because they do not receive aid. This variable is positively correlated with output volatility. This relationship may support the approach of Arellano et al. (2010), who explain the volatility of developing countries in terms of the variability of the aid received, and it is also supports the objective of Peiris and Saxegaard (2007) and Houssa et al. (2010): to define efficient monetary policy rules in the context of sizeable and variable aid transfers. However, this variable is not correlated with the size of the random walk. We also regress the size of the random walk on the mean of aid received, instead of on the standard deviation of aid, and do not find a significant coefficient. Therefore, even if aid seems strongly related to economic volatility, it may not be related to the high weight of trend shocks in the low income countries.

The openness of developing countries to trade is a key channel of transmission of international shocks to domestic countries. We measure trade-openness by the sum of the export and import ratios (both in percent of GDP). Due to the trade liberalization of recent decades, this ratio is growing in most countries. The mean growth rate of trade-openness is $2.26 \%$ for all countries and varies between developed countries (1.57\%), emerging countries (2.47\%), and SSA countries $(2.55 \%)$. When we compare this growth rate with the volatility of output, the relationship is positive and significant (at the 1\% level). This relationship is consistent with Ahmed and Suardi's (2009) finding that trade liberalization is associated with greater output and consumption volatilities. However, we do not find a significant relationship between trade-openness and the structure of shocks.

The last variable that we study is the size of the financial sector, which is measured by domestic credit as a share of GDP. The development of the financial sector is widely known as a key factor in economic stabilization because it allows economies to share risk and to smooth consumption (see Kose et al. (2003) and Özbilgin (2010) among others). We find a strong and significant relationship (at the 1\% level) between our measure of the development of the financial sector and both the output volatility and the size of the random walk. An insufficiently developed financial sector is associated here not only with macroeconomic instability, but also with a high 
weight of trend shocks in the source of fluctuations.

\subsection{Robustness}

We perform simulation and estimation exercises to assess the robustness of the results presented in Section 4.2.

First, the accuracy of the estimation as measured by the standard errors of the random walk size determines the validity of our results, but this may be invalidated if standard errors are too large. To check the robustness of our conclusions, we use the estimated values for the mean and the standard deviations of random walk size to generate 10000 realizations of the 82 values of random walk size. For each simulation, we test the existence of significant relationship between the realized values of random walk size and the macroeconomic variables as performed in Section 4.2. In $93 \%$ of our simulations, the random walk size is significantly correlated at the $1 \%$ level with income as indicated in Section 4.2. We obtain similar comfortable ratios for the two other variables (institutions, $83 \%$, and domestic credit, 99\%).

Second, one country has a random walk size that is very large when compared with the other countries: Chad (4.02). We check that our results are not unduly influenced by this extreme figure. Figure 6 plots the new estimated relations. The random walk size is still significantly related with domestic credit, income and institutions. The relationship with government spending also becomes significant. Interestingly, government spending is positively correlated with the random walk size whereas it is negatively correlated with output volatility (see Figure 6).

Third, the liberalization of trade and finance became very important in developing countries after 1980, and it is during this period that some developing countries became emerging countries, substantially differentiating themselves from SSA countries. We then re-apply the identification strategy using data from after 1980. The results reported in Figure 7 are very close: the size of the random walk is still significantly correlated with the income, institutions, and credit variables. If we suppress ${ }^{24}$ the country with the highest random walk size (Chad), the size of the random walk remains correlated (at the 1\% level) with income, institutions, and domestic credit, and also becomes significantly correlated with government spending at the 5\% level and with trade-openness at the $10 \%$ level.

Finally, we include the parameter $\rho_{z}$ in the set of estimated parameters to reproduce exactly the estimation method of Aguiar and Gopinath (2007). The mean values of the estimated random walk size are very close for the two methods ${ }^{25}$. Therefore, its relationship with the determinants of macroeconomic volatility still holds (see Figure 8). However, these results should be viewed with caution because of the large standard errors of estimated parameters and of the random walk size. As above, if we generate simulated distributions of random walk size, these relations

\footnotetext{
${ }^{24}$ See the supplementary materials for the corresponding figure.

${ }^{25}$ The coefficient of correlation between the estimated values of random walk size with or without a fixed value for $\rho_{z}$ is equal to 0.91
} 
no longer hold. The large standard errors of the random walk size are the consequences of large standard errors ${ }^{26}$ of $\rho_{z}$. If we suppress ${ }^{27}$ the 25 countries with the standard errors of random walk size higher than $100 \%$, the random walk size becomes robustly and significantly correlated with income (at the 5\% level), institutions (at the 5\% level), and domestic credit (at the 10\% level), as in our benchmark case where the value of $\rho_{z}$ is fixed. We prefer this last case because it provides small standard errors for estimated parameters for all the countries of our sample and allows us to identify robustly significant relationships between the random walk size and macroeconomic variables.

To conclude, variations in the weight of trend shocks explain cross-country differences in business cycles and a high weight of trend shocks may be attributable to low income, low institutional quality and an insufficiently developed financial sector. In addition, trend shocks do not appear to be robustly related to volatility of aid received, inflation, and trade-openness, while we cannot conclude for government spending.

\section{Conclusion}

Economic growth is the key for the development of the least poor countries around the world, which are mainly localized in the SSA region. A substantial literature has emphasized the crucial consequences of the average of long-run growth rate for economic prosperity, e.g., Barro and Sala-i-Martin (2003). Our results suggest that the volatility of this long-run growth rate is also important because it seems to be at the origin of the excess volatility of these economies and, therefore, the source of the high welfare costs of fluctuations identified by Pallage and Rob (2003) and Loayza et al. (2007). This conclusion is based on the extension of the work of Aguiar and Gopinath (2007) on emerging countries to a larger sample of countries that includes the lowest developed countries from SSA. Trend shocks have a broad interpretation. Our empirical results call for further theoretical researchers to establish the links between these shocks and the quality of institutions and the size of the domestic credit sector, which are significantly correlated with the size of the random walk across countries.

It is worth mentioning that recent studies challenge the role of trend shocks for emerging countries. Boz et al. (2008) try to improve the model of Aguiar and Gopinath (2007) by adding a learning process to the source of productivity shocks (transitory or permanent). Alvarez-Parra et al. (2011) show that the role of trend shocks is lower when the disaggregation of consumption into durable and nondurable goods is taken into account. Garcia-Cicco et al. (2010) use longterm data for Argentina and find that the small open economy with transitory and trend shocks generates an excessively persistent ratio of the trade balance to output. Based on this failure, they propose to enrich the model with financial shocks. When the extended model is estimated, trend shocks play a negligible role in business cycles. Chang and Fernandez (2010) agree with

\footnotetext{
${ }^{26}$ Large standard errors for $\rho_{z}$ generally occurs when the estimated mean value for the standard deviation $\sigma_{z}$ is small.

${ }^{27}$ See the supplementary materials for the corresponding figure.
} 
Garcia-Cicco et al. (2010) in their comparison of the two leading explanations of emerging market business cycles using Bayesian methods of estimation and they obtain results in favor of the explanation based on financial frictions rather than the explanation based on trend shocks. It will naturally be of interest for future studies to investigate the relevance of financial shocks and frictions to complete our understanding of business cycles in the less developed countries. 


\section{REFERENCES}

Acemoglu, D., Johnson S., Robinson J., 2001. The Colonial Origins of Comparative Development: An Empirical Investigation, American Economic Review, 91(5), 1369-1401.

Acemoglu, D., Johnson S., Robinson J., Thaicharoen Y, 2003. Institutional causes, macroeconomic symptoms: volatility, crises and growth. Journal of Monetary Economics, 50, 49-123.

Aguiar, M., Gopinath, G., 2007. Emerging Market Business Cycles: The Cycle Is the Trend. Journal of Political Economy, 115 , 69-102.

Ahmed, A., Suardi, S., 2009. Macroeconomic volatility, trade and financial liberalization in Africa. World Development review, 37(10), 1623-1636.

Alvarez-Parra, A.F., Marques, L.B., Toledo, M., 2011. Excess Volatility of Consumption in Developed and Emerging Markets: The Role of Durable Goods, Working Paper.

Arellano, C., A. Bulir, T. Lane, L. Lipschitz, 2009. The dynamic implications of foreign aid and its variability, Journal of Development Economics, 88, 87-102.

Barro, R.J., Sala-i-Martin, X., 2003. Economic Growth, 2nd Edition, The MIT Press.

Boz, E., C. Daude, C. Durdu, 2008. Emerging Market Business Cycles Revisited: Learning about the Trend. International Finance Discussion Papers Working Paper $\mathrm{n}^{\circ} 927$.

Burnside, C., 1999. Real Business Cycle Models: Linear Approximation and GMM Estimation, Working Paper.

Chang, R., Fernandez, A., 2010. On the sources of aggregate fluctuations in Emerging Economies. NBER Working Paper 15938.

Chari, V. V., Patrick J. Kehoe, and Ellen McGrattan, 2007. Business Cycle Accounting, Econometrica, 75, 781-836.

Crucini, M. J., Kahn, J., 2003. Tariffs and the great depression revisited. Staff report 172, Federal Reserve Bank of New York.

Garcia-Cicco, J., R. Pancrazi, M. Uribe, 2010. Real Business Cycles in Emerging Countries? American Economic Review 100, 2510-2531.

Houssa, R., Otrok, C., Puslenghea R., 2010. A model for Monetary Policy Analysis for SubSaharan Africa. Open Economic Review, 21, 127-145.

Kollmann, R., 2001. The exchange rate in a dynamic-optimizing business cycle model with nominal rigidities: a quantitative investigation, Journal of International Economics 55, 243262.

Kose, M. A.,2002. Explaining business cycles in small open economies, how much do world price matter? Journal of International Economics, 56, 299-327. 
Kose, N. A., Riezman, R., 2001. Trade shocks and macroeconomic fluctuation in Africa. Journal of Development Economic, 65, 55-80.

Kose, N.A., Prasad, E., Terrones, M.E., 2003. Financial Integration and Macroeconomic Volatility, IMF Working Papers 03/50, International Monetary Fund.

Kydland, F. E., Zarazaga, E. J.,1997. Is the business cycle of Argentina "different”? Economic Review, Federal Reserve Bank of Dallas PP. 21-36.

Lagos, R., 2006. A model of total factor productivity (TFP). Review of Economic Studies, 73, 983-1007.

Loayza, N.V., Ranciere, R., Serven, L., Ventura, J., 2007. Macroeconomic volatility and welfare in developing countries: an introduction. The World Bank Economic Review, 21, 343-357.

Mendoza, E.G.,1991. Real business cycles in a small open economy. American Economic Review, 81, 797-818.

Mendoza, E.G.,1995. The terms of trade, the real exchange rate, and Economic fluctuation. International Economic Review, 36,101-137.

Monacelli, T., 2004. Into the Mussa puzzle: monetary policy regimes and the real exchange rate in a small open economy, Journal of International Economics, 62, 191-217.

Neumeyer, P. A., Perri, F., 2005. Business Cycles in Emerging Economies: The Role of Interest. Journal of Monetary Economics, 52, 345-380.

Özbilgin, H.M., 2010. Financial market participation and the developing country business cycle, Journal of Development Economics, 92, 125-137.

Pallage, S., Robe, M., 2003. The Welfare Cost of Economic Fluctuations in Developing Countries. International Economic Review, 44(2), 677-698.

Peiris, J.-S., Saxegaard, M., 2007. An estimated DSGE model for monetary policy analysis in low-income Countries. International Monetary Fund. African Dept, ${ }^{\circ}{ }^{\circ}$ 2007-2282.

Raddatz, C., 2007. Are External Schocs Responsible for the Instability of Output in Lowincome Countries? Journal of Development Economics, 84, 155-187.

Ramey, G., Ramey, V.A.,1995. Cross-Country Evidence on the Link Between Volatility and Growth .American Economic Review, 85, 1138-1151.

Rand, J., Tarp, F., 2002. Business Cycles in Developing Countries: Are They Different? World Development, Elsevier, 30, 2071-2088.

Restrepo-Echavarria, P., 2011. Macroeconomic Volatility: The Role of the Informal Economy, Working Paper. 
Uhlig, Harald, 1997. A toolkit for analyzing nonlinear economic dynamic models easily: MATLAB programs. http://www2.wiwi.hu-berlin.de/institute/wpol/html/toolkit.htm. 


\section{DATA APPENDIX}

- All macroeconomic data are from the World Bank database "World Development Indicators", CD-ROM version, 2008. The sample period for most of the included countries is 1960-2006, but, as specified, below the date for the first observation can vary for some countries.

- The consumption is the log of the household final consumption expenditure in local currency unit divided by the population.

- The output is the log of the Gross National Product (GNP) per capita in local currency unit or in constant USD 2000.

- The size of the credit market is measured by the domestic credit provided by banking sector in percentage of GDP.

- The government spending is measured by the general government final consumption expenditure in percentage of GDP.

- The aid received is measured by the total foreign aid received by countries in percentage of GNI.

- The ratio of net-exports to output is the difference between the ratios of exportation and importation and the ratio of trade-openeness is the sum of these two ratios, respectively defined as the exports of goods and services in percentage of GDP and the imports of goods and services in percentage of GDP.

- Population is measured by the total population.

- The quality of institutions is the average of "the rule of law" provided by the "World Governance Indicators, 1996-2008" (http://wbi.worldbank.org) over the sample period 1996-2008.

- For each country, we give the starting date of the sample and its short name used in Tables and Figures.

- Developed: Australia (AUS,1971); Austria (AUT,1971); Belgium (BEL,1971); Canada (CAN,1960); Denmark (DNK,1966); Finland (FIN,1960); France (FRA,1970); Germany (DEU,1971); Greece (GRC,1960); Iceland (ISL, 1960); Ireland (IRL,1971); Italy (ITA, 1960); Japan (JPN,1960); Luxembourg (LUX,1960); Netherlands (NLD,1971); New Zealand (NZL,1971); Norway (NOR,1960); Portugal (PRT,1971); Spain (ESP,1971); Sweden (SWE,1960); Switzerland (CHE,1960); United Kingdom(GBR,1970)

- Emerging: Korea, Rep. (KOR,1960); Kenya (KEN,1979); South Africa (ZAF,1960); Algeria (DZA,1969); Egypt, Arab Rep. (EGY,1974); Iran, Islamic Rep.(IRN,1965); Morocco (MAR,1966); Tunisia (TUN,1961); Hungary (HUN,1965); Turkey (TUR,1987); China (CHN,1970); India (IND,1960); Indonesia (IDN,1979); Malaysia (MYS,1960); Pakistan (PAK,1967); Philippines (PHL,1960); Thailand (THA,1960); Argentina (ARG,1960); Brazil (BRA,1970); Chile (CHL,1960); Colombia (COL,1960); Costa Rica (CRI,1960); Ecuador (ECU,1965); Mexico (MEX,1960); Panama (PAN,1980); Peru (PER,1960); Uruguay (URY,1960); Venezuela (VEN,1974)

- SSA: Benin (BEN,1982); Botswana (BWA,1975); Burkina Faso (BFA,1983); Cameroon (CMR,1975); Cape Verde (CPV,1986); Chad (TCD,1991); Comoros (COM,1980); Congo, 
Dem. Rep.(ZAR,1968); Ivory Coast (CIV,1965); Ethiopia (ETH,1981); Gabon (GAB,1980); Gambia, The (GMB,1966); Ghana (GHA,1967); Guinea (GIN,1986); Guinea-Bissau (GNB,1987); Lesotho (LSO,1970); Madagascar (MDG,1971); Malawi (MWI,1973); Mali (MLI,1979); Mauritania (MRT,1965); Mauritius (MUS,1980); Mozambique (MOZ,1980); Namibia (NAM,1980); Rwanda (RWA,1965); Senegal (SEN,1965); Seychelles (SYC,1984); Sudan (SDN,1976); Swaziland (SWZ,1980); Togo (TGO,1980); Uganda (UGA,1982); Zambia (ZMB,1970); Zimbabwe (ZWE,1975) 
TABLES AND FIGURES

Figure 1 - Economic development and business cycle moments
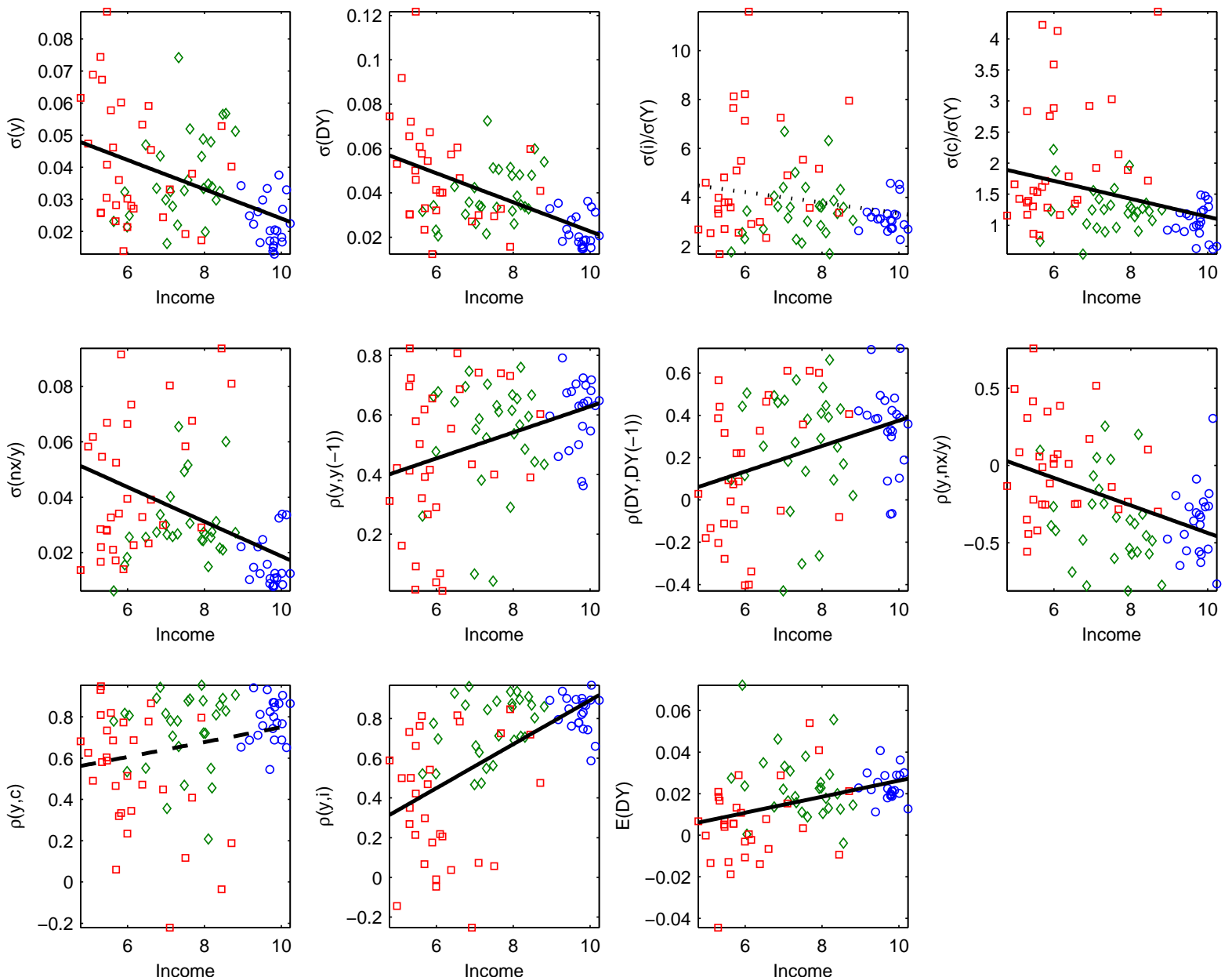

Notes: The variable "Income" is the average of the log of Gross Domestic Product per capita in constant USD of 2000. The variable $z$ is the cyclical component of $\log (Z)$ using the HP filter (with a coefficient equal to 100), $\sigma(z)$ denotes the standard deviation of the series $z$, $\rho(y, z)$ is the correlation coefficient between output $y$ and the variable $z$, for $z=\{y, i, c, n x / y\}$, and $E(D Y)$ is the mean of the growth rate of output $D Y=\log \left(Y / Y_{-1}\right)$. The solid, dashed, and dotted lines are the outcome of a linear regression with a coefficient significantly different from 0 at the 1,5 , and 10 percent levels, respectively. If the coefficient is not significantly different from 0 at the 1,5 or 10 level, there is no line. 
Figure 2 - Sensitivity of moments to the relative volatility of trend shocks

(a)

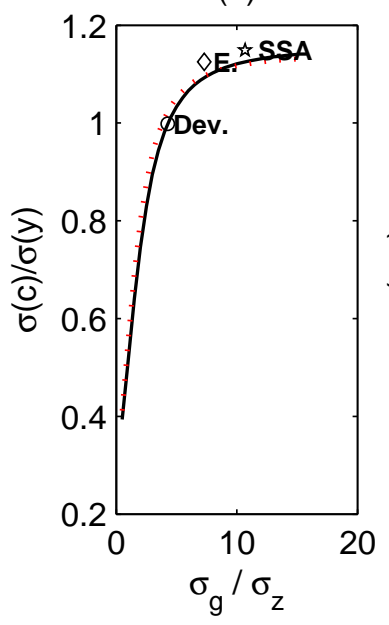

(e)

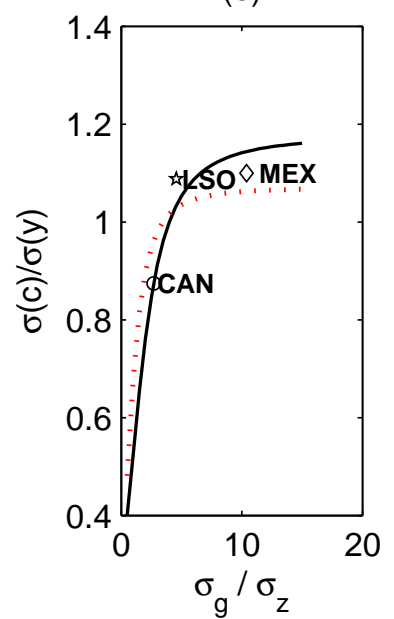

(b)

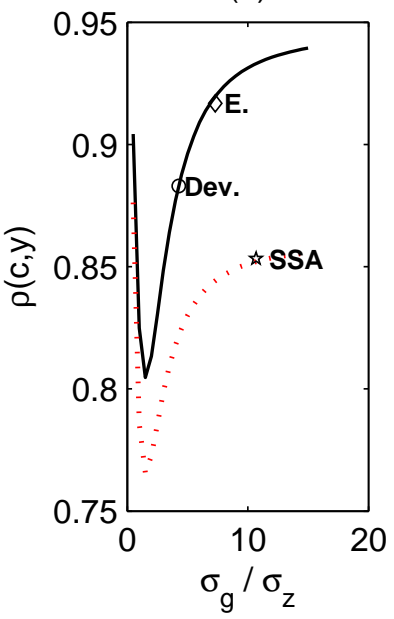

(f)

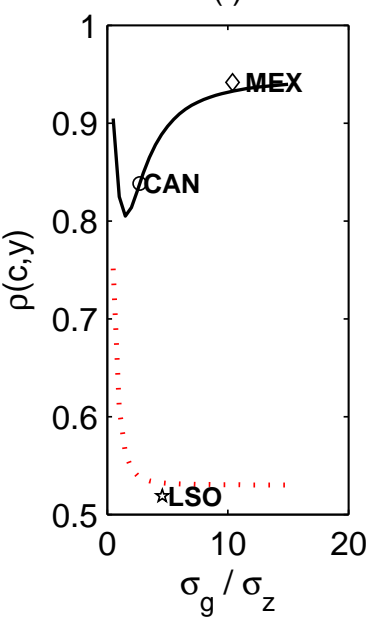

(c)

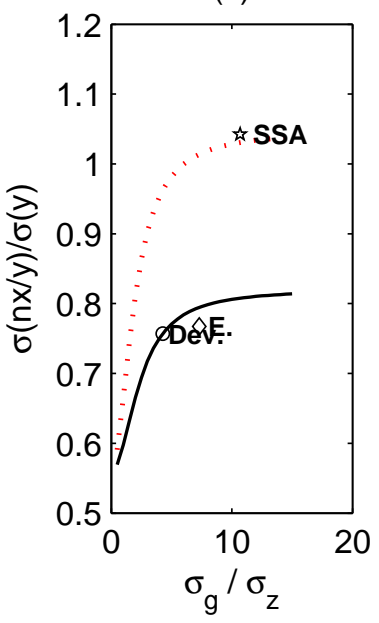

(g)

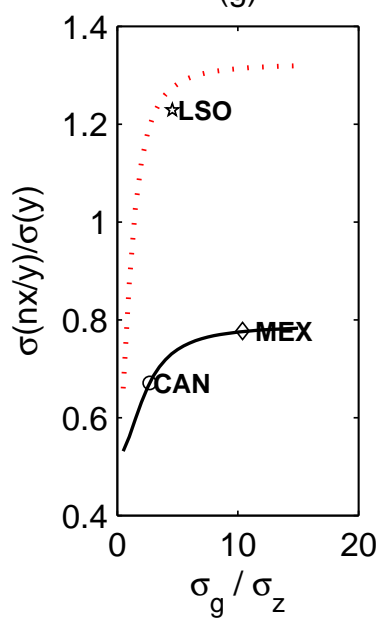

(d)

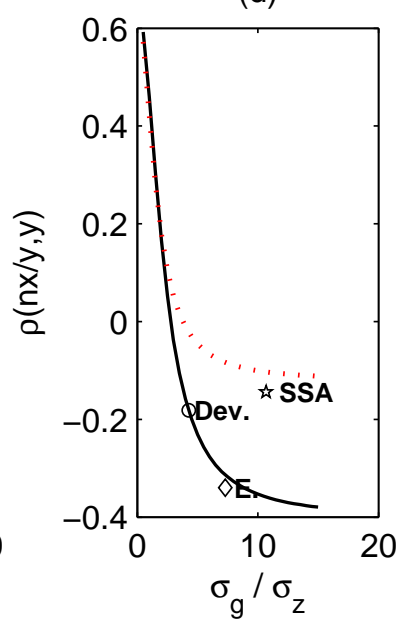

(h)

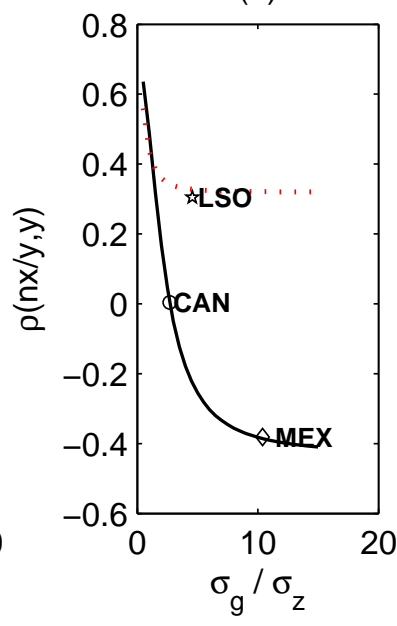

Notes: Moments for consumption and net exports (relative volatility to output and correlation with output) as a function of alternative $\sigma_{g} / \sigma_{z}$. Panels (a)-(d). The solide lines are for the values of $\sigma_{z}, \rho_{r}, \phi$, and $\mu_{g}$ reported in the Column "Developed" of Table 3. The dotted lines are for the same values except for $\rho_{g}$, which is fixed to the value reported in the column "SSA" in Table 3. Panels (e)-(h). The solde lines are for the values of $\sigma_{z}, \rho_{r}, \phi$, and $\mu_{g}$ reported in the Column "Canada" of Table 3. The dotted lines are for the same values except for $\rho_{g}$, which is fixed to the value reported in the column "Lesotho" in Table 3. For circle, diamond, and star marks, all values of parameters are taken in the corresponding columns of Table 3. 
Figure 3 - Moments for the data and the model
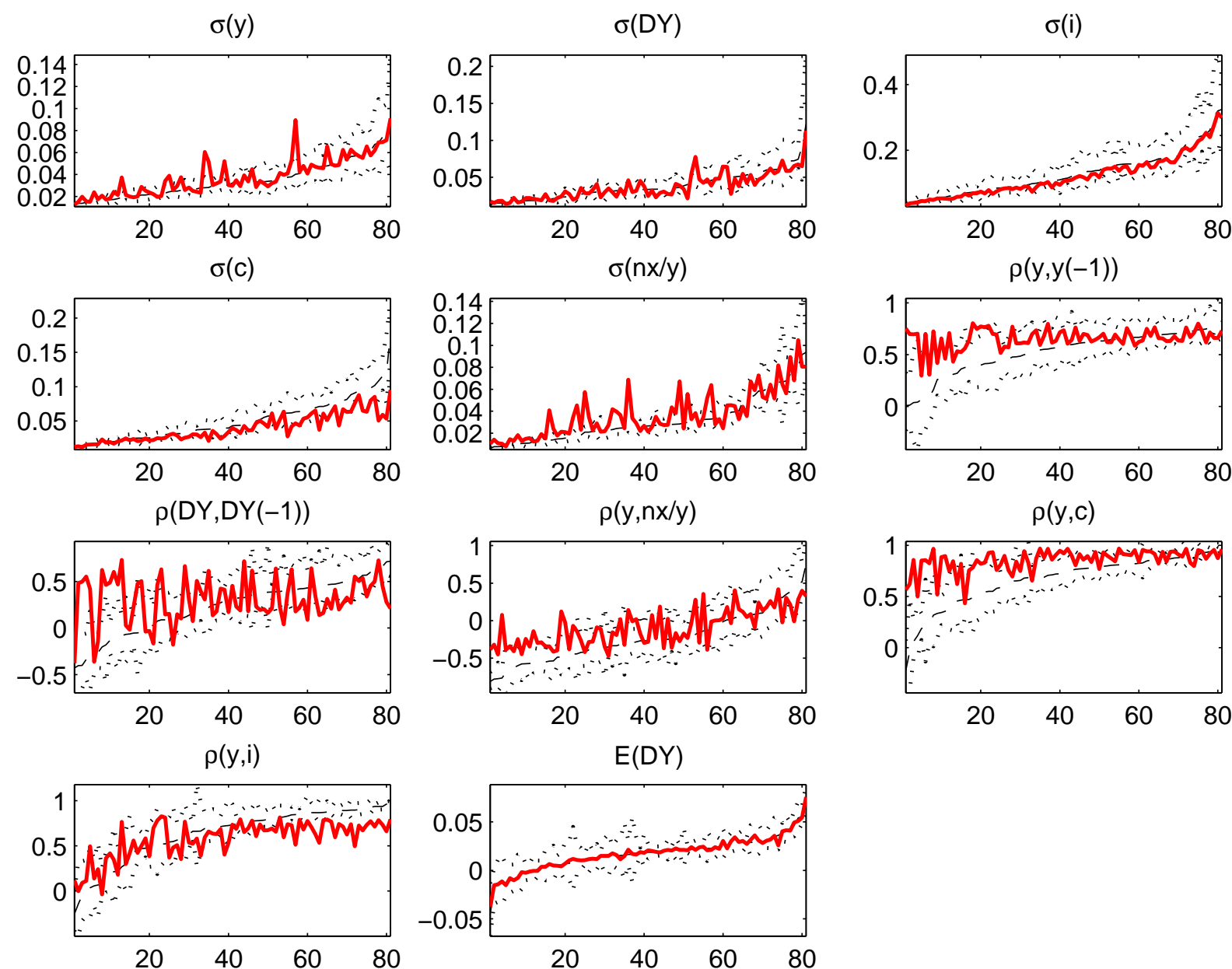

Notes: The dashed lines are the mean values of moments for the data (dotted lines are mean values $+/-$ two standard deviations) and the solid lines are the moments predicted by the model. For each moment, data are sorted in increasing order with respect to the mean value for the data. The variable $z$ is the cyclical component of $\log (Z)$ using the HP filter (with a coefficient equal to 100), $\sigma(z)$ denotes the standard deviation of the series $z, \rho(y, z)$ is the correlation coefficient between output $y$ and the variable $z$, for $z=\{y, i, c, n x / y\}$, and $E(D Y)$ is the mean of the growth rate of output $D Y=\log \left(Y / Y_{-1}\right)$. 
Figure 4 - Output volatility and macroeconomic variables
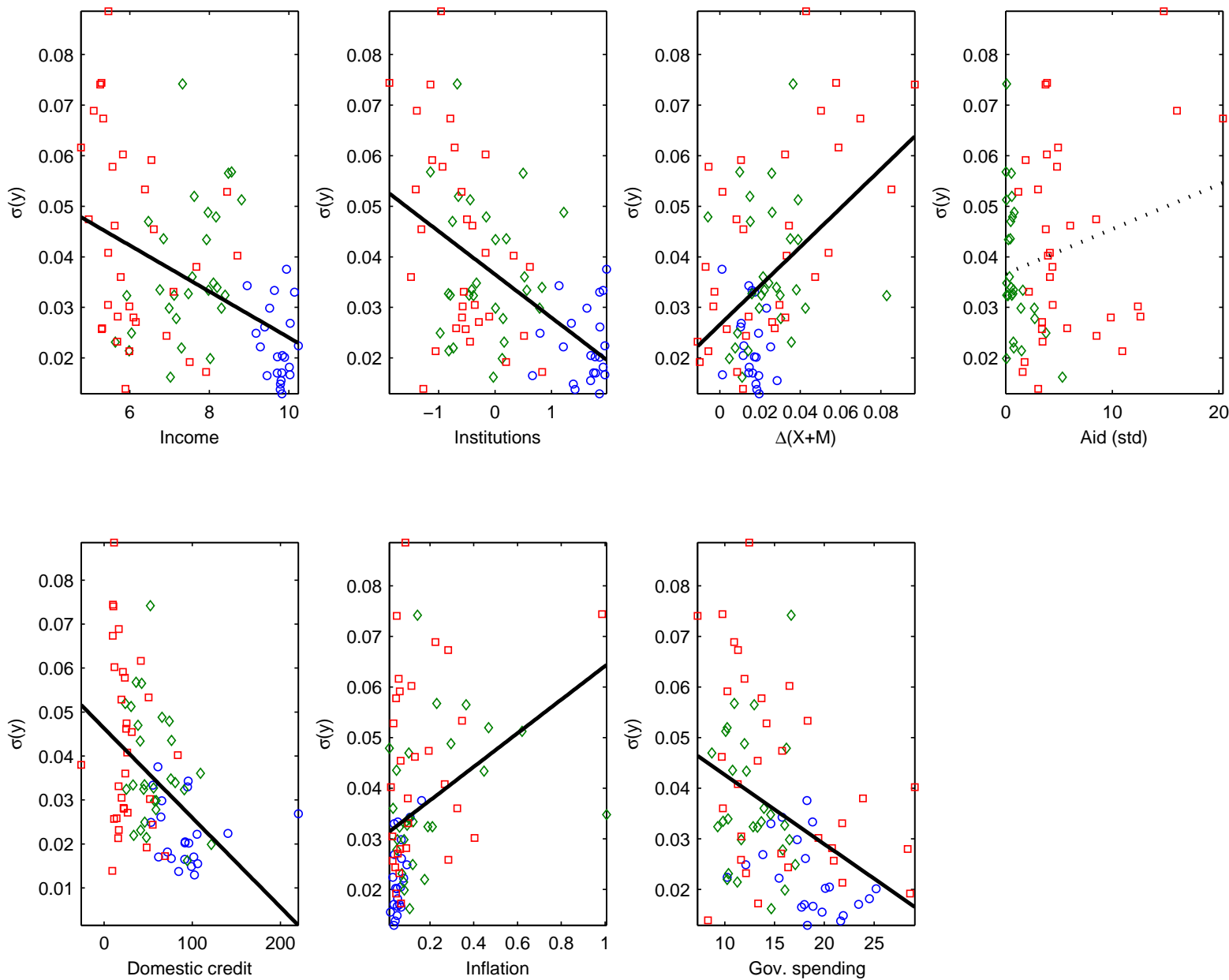

Notes: $\sigma(y)$ stands for the standard deviation of output. The square symbol denotes SSA countries, the diamond symbol denotes emerging countries, and the circle symbol denotes developed countries. The solid, dashed, and dotted lines are the outcome of a linear regression with a coefficient significantly different from 0 at the 1,5 , and 10 percent levels, respectively. If the coefficient is not significantly different from 0 at the 1,5 or 10 level, there is no line. Variables are: the mean of real income per capita, the quality of the institution, the growth rate of trade openness, the volatility of aid received by countries as a percent of income, the mean of the size of the domestic credit as a percent of GDP, the mean of the inflation rate, and the mean of the size of government spending as a percent of GDP. See the Data Appendix for details on the data. 
Figure 5 - The size of random walk and macroeconomic variables
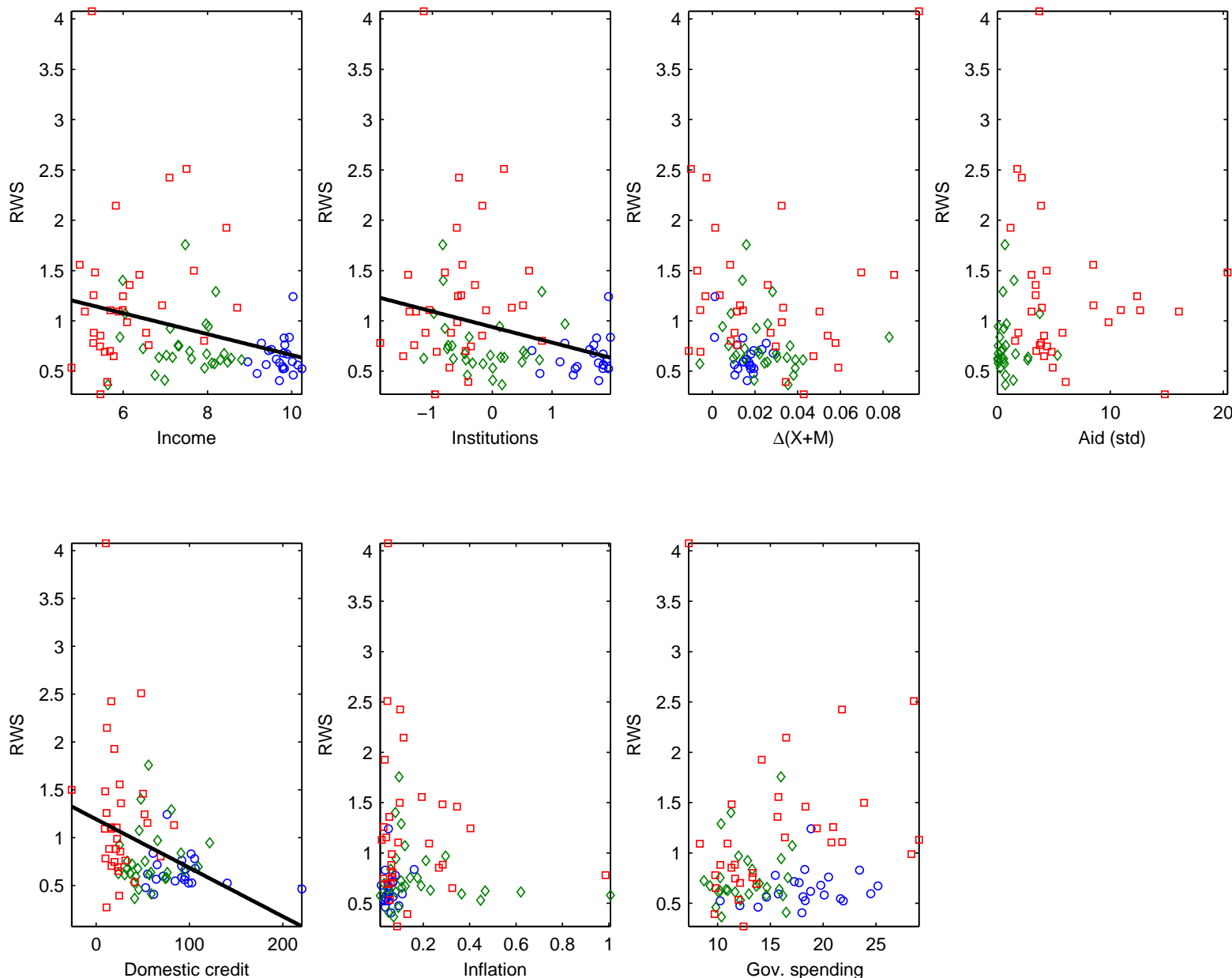

Notes: RWS stands for the random walk size. The square symbol denotes SSA countries, the diamond symbol denotes emerging countries, and the circle symbol denotes developed countries. The solid, dashed, and dotted lines are the outcome of a linear regression with a coefficient significantly different from 0 at the 1,5 , and 10 percent levels, respectively. If the coefficient is not significantly different from 0 at the 1,5 or 10 level, there is no line. Variables are: the mean of real income per capita, the quality of the institution, the growth rate of trade openness, the volatility of aid received by countries as a percent of income, the mean of the size of the domestic credit as a percent of GDP, the mean of the inflation rate, and the mean of the size of government spending as a percent of GDP. See the Data Appendix for details on the data. 
Figure 6 - The size of random walk and macroeconomic variables (without Chad)
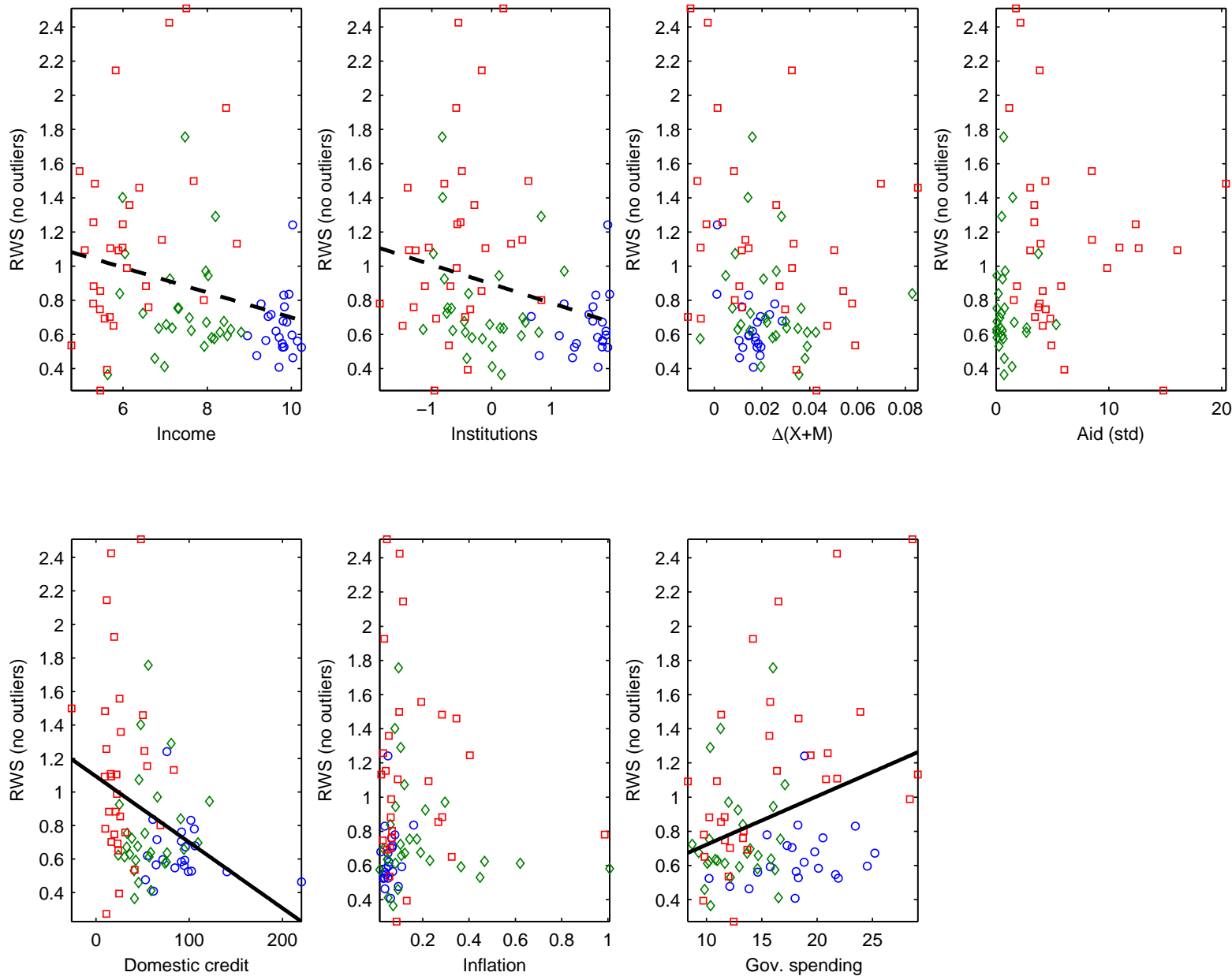

Notes: RWS stands for the random walk size. The square symbol denotes SSA countries, the diamond symbol denotes emerging countries, and the circle symbol denotes developed countries. The solid, dashed, and dotted lines are the outcome of a linear regression with a coefficient significantly different from 0 at the 1,5 , and 10 percent levels, respectively. If the coefficient is not significantly different from 0 at the 1,5 or 10 level, there is no line. Variables are: the mean of real income per capita, the quality of the institution, the growth rate of trade openness, the volatility of aid received by countries as a percent of income, the mean of the size of the domestic credit as a percent of GDP, the mean of the inflation rate, and the mean of the size of government spending as a percent of GDP. See the Data Appendix for details on the data. 
Figure 7 - The size of random walk and macroeconomic variables (data after 1980)
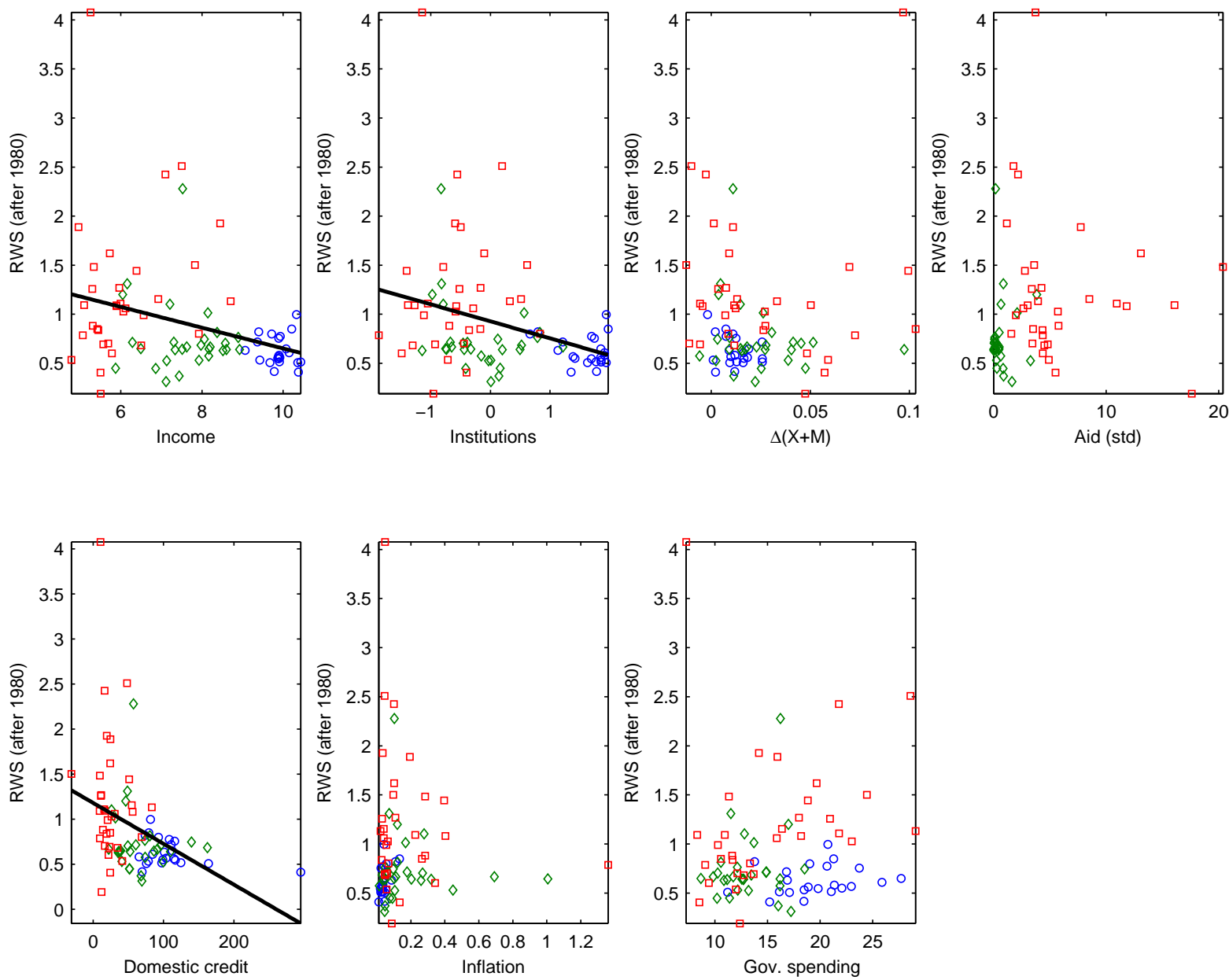

RWS stands for the random walk size. The square symbol denotes SSA countries, the diamond symbol denotes emerging countries, and the circle symbol denotes developed countries. The solid, dashed, and dotted lines are the outcome of a linear regression with a coefficient significantly different from 0 at the 1,5 , and 10 percent levels, respectively. If the coefficient is not significantly different from 0 at the 1,5 or 10 level, there is no line. Variables are: the mean of real income per capita, the quality of the institution, the growth rate of trade openness, the volatility of aid received by countries as a percent of income, the mean of the size of the domestic credit as a percent of GDP, the mean of the inflation rate, and the mean of the size of government spending as a percent of GDP. See the Data Appendix for details on the data. 
Figure 8 - The size of random walk and macroeconomic variables (when $\rho_{z}$ is estimated)
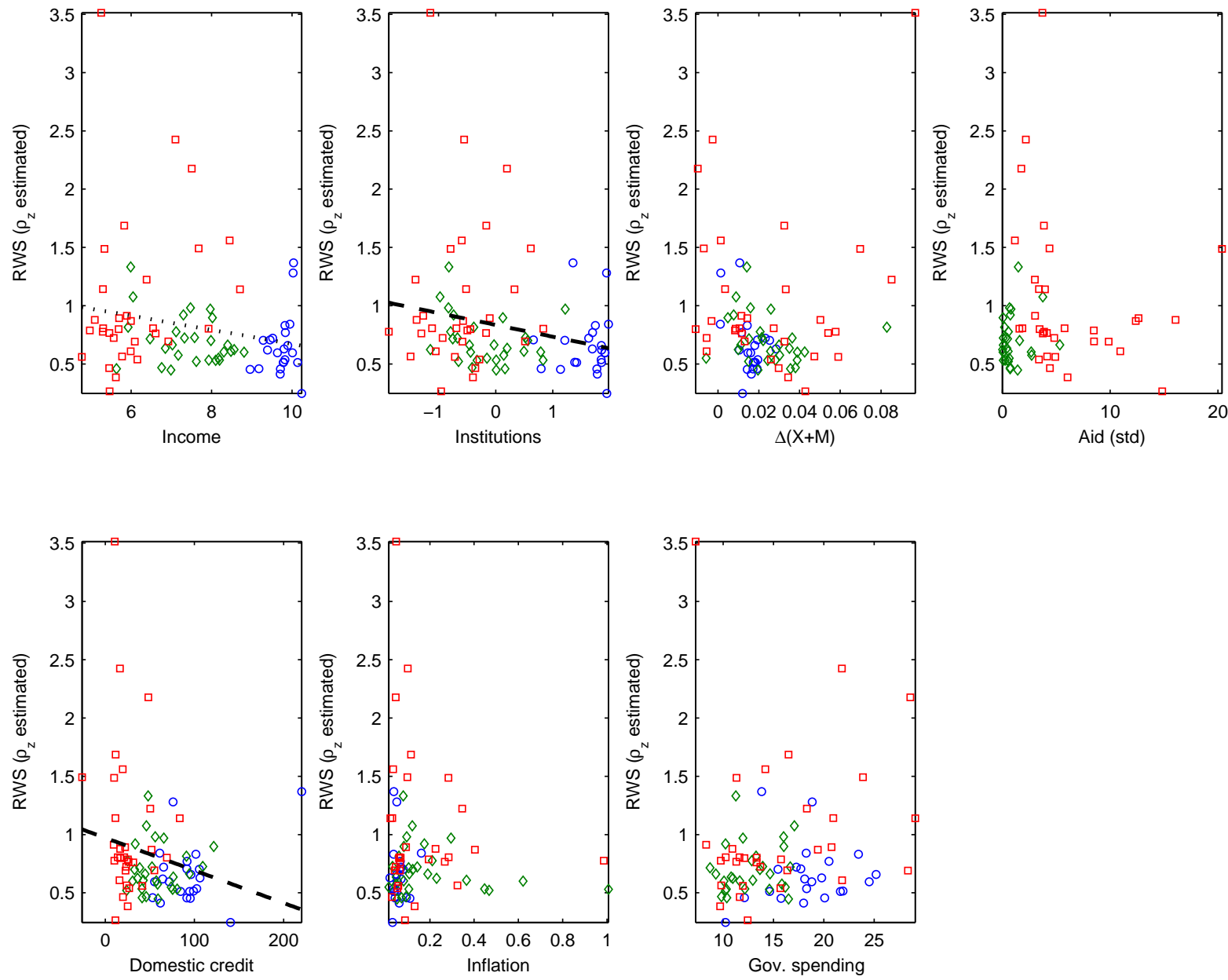

Notes: RWS stands for the random walk size. The square symbol denotes SSA countries, the diamond symbol denotes emerging countries, and the circle symbol denotes developed countries. The solid, dashed, and dotted lines are the outcome of a linear regression with a coefficient significantly different from 0 at the 1,5 , and 10 percent levels, respectively. If the coefficient is not significantly different from 0 at the 1,5 or 10 levels, there is no line. Variables are: the mean of real income per capita, the quality of the institution, the growth rate of trade openness, the volatility of aid received by countries as a percent of income, the mean of the size of the domestic credit as a percent of GDP, the mean of the inflation rate, and the mean of the size of government spending as a percent of GDP. See the Data Appendix for details on the data. 
Table 1 - Moments (average for each group of countries)

Data

Model

\begin{tabular}{lcccccc}
\hline \hline Moments & Developed & Emerging & SSA & Developed & Emerging & SSA \\
\hline$\sigma(\mathbf{y})$ & 2.25 & 3.71 & 4.25 & 2.27 & 3.83 & 5.16 \\
& $(0.28)$ & $(0.66)$ & $(0.82)$ & $(0.18)$ & $(0.36)$ & $(0.42)$ \\
$\sigma(\mathbf{D Y})$ & 2.26 & 3.90 & 4.98 & 2.22 & 3.84 & 4.90 \\
& $(0.31)$ & $(0.72)$ & $(1.02)$ & $(0.19)$ & $(0.38)$ & $(0.43)$ \\
$\sigma(\mathbf{i}) / \sigma(\mathbf{y})$ & 3.12 & 3.43 & 4.13 & 2.82 & 3.01 & 3.23 \\
$\sigma(\mathbf{i})$ & 7.02 & 12.71 & 17.54 & 6.41 & 11.54 & 16.68 \\
& $(1.01)$ & $(2.26)$ & $(3.05)$ & $(0.53)$ & $(1.15)$ & $(1.44)$ \\
$\sigma(\mathbf{c}) / \sigma(\mathbf{y})$ & 1.04 & 1.22 & 1.76 & 0.95 & 1.03 & 1.05 \\
$\sigma(\mathbf{c})$ & 2.33 & 4.54 & 7.49 & 2.16 & 3.96 & 5.43 \\
& $(0.32)$ & $(0.77)$ & $(1.23)$ & $(0.19)$ & $(0.41)$ & $(0.48)$ \\
$\sigma(\mathbf{n x} / \mathbf{y}) / \sigma(\mathbf{y})$ & 0.69 & 0.80 & 1.19 & 0.77 & 0.86 & 1.15 \\
$\sigma(\mathbf{n x} / \mathbf{y})$ & 1.55 & 2.97 & 5.07 & 1.75 & 3.30 & 5.91 \\
& $(0.23)$ & $(0.44)$ & $(1.00)$ & $(0.13)$ & $(0.31)$ & $(0.45)$ \\
$\rho(\mathbf{y}, \mathbf{y}(-\mathbf{1}))$ & 0.61 & 0.53 & 0.45 & 0.64 & 0.63 & 0.70 \\
& $(9.87)$ & $(10.75)$ & $(13.14)$ & $(2.72)$ & $(3.02)$ & $(2.14)$ \\
$\rho(\mathbf{D Y}, \mathbf{D Y}(-\mathbf{1}))$ & 0.34 & 0.25 & 0.13 & 0.22 & 0.24 & 0.44 \\
& $(14.03)$ & $(12.87)$ & $(16.03)$ & $(6.65)$ & $(7.02)$ & $(5.69)$ \\
$\rho(\mathbf{y}, \mathbf{n x} / \mathbf{y})$ & -0.37 & -0.35 & 0.00 & -0.12 & -0.16 & 0.01 \\
& $(14.16)$ & $(15.45)$ & $(14.60)$ & $(6.20)$ & $(5.68)$ & $(4.38)$ \\
$\rho(\mathbf{y}, \mathbf{c})$ & 0.78 & 0.73 & 0.52 & 0.87 & 0.88 & 0.80 \\
& $(6.84)$ & $(8.22)$ & $(11.82)$ & $(1.89)$ & $(2.04)$ & $(2.78)$ \\
$\rho(\mathbf{y}, \mathbf{i})$ & 0.83 & 0.75 & 0.36 & 0.69 & 0.65 & 0.43 \\
& $(5.01)$ & $(7.82)$ & $(14.84)$ & $(2.58)$ & $(2.99)$ & $(4.11)$ \\
$\mathbf{E}(\mathbf{D Y})$ & 0.02 & 0.02 & 0.01 & 0.02 & 0.02 & 0.01 \\
& $(0.44)$ & $(0.74)$ & $(0.99)$ & $(0.32)$ & $(0.45)$ & $(0.49)$ \\
\hline
\end{tabular}

Notes: GMM estimates of the moments for the data and for the model with standard errors in parentheses. All standard errors and the standard deviations are in percentage. For each type of country, the table reports the average values for the group of countries. The variable $z$ is the cyclical component of $\log (Z)$ using the HP filter (with a coefficient equal to 100), $\sigma(z)$ denotes the standard deviation of the series $z, \rho(y, z)$ is the correlation coefficient between output $y$ and the variable $z$, for $z=\{y, i, c, n x / y\}$, and $E(D Y)$ is the mean of the growth rate of output $D Y=\log \left(Y / Y_{-1}\right)$. 
Table 2 - Moments for three countries

Data

Model

\begin{tabular}{lcccccc}
\hline \hline Moments & Canada & Mexico & Lesotho & Canada & Mexico & Lesotho \\
\hline$\sigma(\mathbf{y})$ & 2.02 & 3.24 & 6.02 & 1.93 & 2.93 & 6.56 \\
& $(0.31)$ & $(0.57)$ & $(1.18)$ & $(0.12)$ & $(0.42)$ & $(0.59)$ \\
$\sigma(\mathbf{D Y})$ & 2.02 & 3.28 & 6.74 & 1.87 & 3.02 & 5.86 \\
& $(0.26)$ & $(0.46)$ & $(1.67)$ & $(0.15)$ & $(0.45)$ & $(0.62)$ \\
$\sigma(\mathbf{i}) / \sigma(\mathbf{y})$ & 2.61 & 3.35 & 2.56 & 2.54 & 2.97 & 2.20 \\
$\sigma(\mathbf{i})$ & 5.28 & 10.85 & 15.43 & 4.91 & 8.69 & 14.44 \\
& $(0.79)$ & $(2.00)$ & $(2.47)$ & $(0.32)$ & $(1.34)$ & $(1.19)$ \\
$\sigma(\mathbf{c}) / \sigma(\mathbf{y})$ & 1.00 & 1.36 & 1.28 & 0.88 & 1.10 & 1.09 \\
$\sigma(\mathbf{c})$ & 2.02 & 4.40 & 7.73 & 1.69 & 3.23 & 7.14 \\
& $(0.30)$ & $(0.82)$ & $(1.09)$ & $(0.22)$ & $(0.55)$ & $(0.50)$ \\
$\sigma(\mathbf{n x} / \mathbf{y}) / \sigma(\mathbf{y})$ & 0.53 & 0.67 & 1.52 & 0.67 & 0.78 & 1.23 \\
$\sigma(\mathbf{n x} / \mathbf{y})$ & 1.07 & 2.16 & 9.15 & 1.30 & 2.28 & 8.06 \\
& $(0.09)$ & $(0.46)$ & $(2.57)$ & $(0.09)$ & $(0.37)$ & $(0.69)$ \\
$\rho(\mathbf{y}, \mathbf{y}(-\mathbf{1}))$ & 0.63 & 0.59 & 0.42 & 0.65 & 0.60 & 0.78 \\
& $(9.45)$ & $(9.91)$ & $(18.30)$ & $(2.42)$ & $(2.85)$ & $(2.71)$ \\
$\rho(\mathbf{D Y}, \mathbf{D Y}(-\mathbf{1}))$ & 0.32 & 0.25 & 0.09 & 0.23 & 0.14 & 0.63 \\
& $(14.18)$ & $(12.61)$ & $(14.47)$ & $(6.22)$ & $(6.52)$ & $(9.39)$ \\
$\rho(\mathbf{y}, \mathbf{n x} / \mathbf{y})$ & -0.09 & -0.45 & 0.35 & 0.00 & -0.38 & 0.30 \\
& $(23.86)$ & $(12.84)$ & $(18.27)$ & $(11.10)$ & $(5.69)$ & $(7.80)$ \\
$\rho(\mathbf{y}, \mathbf{c})$ & 0.83 & 0.86 & 0.33 & 0.84 & 0.94 & 0.52 \\
& $(6.38)$ & $(5.08)$ & $(16.06)$ & $(2.47)$ & $(1.61)$ & $(7.73)$ \\
$\rho(\mathbf{y}, \mathbf{i})$ & 0.78 & 0.91 & 0.54 & 0.74 & 0.73 & 0.37 \\
$\mathbf{E}(\mathbf{D Y})$ & $(5.65)$ & $(3.14)$ & $(13.81)$ & $(2.32)$ & $(1.28)$ & $(6.84)$ \\
& 0.02 & 0.02 & 0.03 & 0.02 & 0.02 & 0.03 \\
& $(0.38)$ & $(0.58)$ & $(0.90)$ & $(0.25)$ & $(0.29)$ & $(0.58)$ \\
\hline
\end{tabular}

Notes: GMM estimates of the moments for the data and for the model with standard errors in parentheses. All standard errors and the standard deviations are in percentage. The variable $z$ is the cyclical component of $\log (Z)$ using the HP filter (with a coefficient equal to 100 ), $\sigma(z)$ denotes the standard deviation of the series $z, \rho(y, z)$ is the correlation coefficient between output $y$ and the variable $z$, for $z=\{y, i, c, n x / y\}$, and $E(D Y)$ is the mean of the growth rate of output $D Y=\log \left(Y / Y_{-1}\right)$. 
Table 3 - Estimated parameters

\begin{tabular}{lcccccc}
\hline \hline Parameter & Developed & Emerging & SSA & Canada & Mexico & Lesotho \\
\hline$\sigma_{\mathbf{g}}$ & 2.89 & 5.33 & 6.20 & 2.25 & 4.62 & 5.86 \\
& $(0.30)$ & $(0.59)$ & $(0.57)$ & $(0.36)$ & $(0.79)$ & $(0.60)$ \\
$\sigma_{\mathbf{z}}$ & 0.68 & 0.73 & 0.58 & 0.83 & 0.44 & 1.28 \\
& $(3.47)$ & $(18.80)$ & $(43.97)$ & $(0.06)$ & $(0.19)$ & $(1.08)$ \\
$\rho_{\mathbf{g}}$ & -0.13 & -0.11 & 0.05 & -0.13 & -0.18 & 0.40 \\
& $(4.69)$ & $(4.09)$ & $(4.25)$ & $(4.40)$ & $(2.78)$ & $(5.90)$ \\
$\mu_{g}$ & 1.02 & 1.02 & 1.01 & 1.02 & 1.02 & 1.03 \\
& $(0.32)$ & $(0.45)$ & $(0.49)$ & $(0.25)$ & $(0.29)$ & $(0.58)$ \\
$\phi$ & 0.22 & 0.30 & 0.26 & 0.27 & 0.18 & 0.50 \\
& $(4.98)$ & $(7.55)$ & $(7.73)$ & $(3.56)$ & $(2.00)$ & $(13.47)$ \\
$\mathbf{R W S}$ & 0.65 & 0.76 & 1.24 & 0.58 & 0.68 & 2.15 \\
& $(2.06)$ & $(2.11)$ & $(6.74)$ & $(0.21)$ & $(0.20)$ & $(2.54)$ \\
\hline $\mathbf{Q}$ & 5.03 & 4.91 & 4.39 & 5.34 & 4.60 & 5.12 \\
$\mathbf{p}-$ value & 0.54 & 0.56 & 0.63 & 0.50 & 0.60 & 0.53 \\
\hline
\end{tabular}

Notes: GMM estimates of the structural parameters with standard errors in parentheses (in percentage). For each type of country, the table reports the average values for the group of countries. RWS stands for random walk size, $\sigma_{g}$ for standard deviation of trend shocks, $\sigma_{z}$ for standard deviation of transitory shocks, $\rho_{g}$ for persistence of trend shocks, $\mu_{g}$ for productivity long-run mean growth rate, and $\phi$ for capital adjustment costs parameter. 
Table 4 - Estimated parameters (including $\rho_{z}$ )

\begin{tabular}{lccc}
\hline Parameter & Developed & Emerging & SSA \\
\hline$\sigma_{\mathbf{g}}$ & 2.89 & 5.18 & 6.43 \\
& $(0.41)$ & $(0.83)$ & $(0.81)$ \\
$\sigma_{\mathbf{z}}$ & 0.75 & 0.86 & 0.56 \\
& $(4.25)$ & $(3.65)$ & $(4.68)$ \\
$\rho_{\mathbf{g}}$ & -0.12 & -0.09 & -0.01 \\
& $(6.08)$ & $(8.17)$ & $(7.14)$ \\
$\rho_{\mathbf{z}}$ & 0.68 & 0.23 & -0.44 \\
& $(446257)$ & $(192977)$ & $(85956)$ \\
$\mu_{g}$ & 1.02 & 1.02 & 1.01 \\
& $(0.35)$ & $(0.50)$ & $(0.55)$ \\
$\phi$ & 0.38 & 0.31 & 0.26 \\
& $(9.27)$ & $(12.05)$ & $(9.70)$ \\
$\mathbf{R W S}$ & 0.66 & 0.70 & 1.04 \\
& $(2443)$ & $(82397183)$ & $(5048)$ \\
\hline $\mathbf{Q}$ & 4.88 & 4.64 & 4.25 \\
$\mathbf{p}-$ value & 0.44 & 0.47 & 0.52 \\
\hline
\end{tabular}

Notes: GMM estimates of the structural parameters with standard errors in parentheses (in percentage). For each type of country, the table reports the average values for the group of countries. RWS stands for random walk size, $\sigma_{g}$ for standard deviation of trend shocks, $\sigma_{z}$ for standard deviation of transitory shocks, $\rho_{g}$ for persistence of trend shocks, $\rho_{z}$ for persistence of transitory shocks, $\mu_{g}$ for productivity long-run mean growth rate, and $\phi$ for capital adjustment costs parameter. 
Table 5 - Moments for the model (when $\rho_{z}$ is estimated)

\begin{tabular}{lccc}
\hline Moments & Developed & Emerging & SSA \\
\hline$\sigma(\mathbf{y})$ & 2.27 & 3.81 & 5.19 \\
& $(0.20)$ & $(0.42)$ & $(0.48)$ \\
$\sigma(\mathbf{D Y})$ & 2.23 & 3.91 & 5.32 \\
& $(0.21)$ & $(0.45)$ & $(0.57)$ \\
$\sigma(\mathbf{i}) / \sigma(\mathbf{y})$ & 2.76 & 2.97 & 3.19 \\
$\sigma(\mathbf{i})$ & 6.27 & 11.32 & 16.56 \\
& $(0.62)$ & $(1.41)$ & $(1.68)$ \\
$\sigma(\mathbf{c}) / \sigma(\mathbf{y})$ & 0.98 & 1.03 & 1.04 \\
$\sigma(\mathbf{c})$ & 2.23 & 3.94 & 5.38 \\
& $(0.22)$ & $(0.46)$ & $(0.54)$ \\
$\sigma(\mathbf{n x} / \mathbf{y}) / \sigma(\mathbf{y})$ & 0.78 & 0.86 & 1.14 \\
$\sigma(\mathbf{n x} / \mathbf{y})$ & 1.76 & 3.28 & 5.91 \\
& $(0.16)$ & $(0.34)$ & $(0.52)$ \\
$\rho(\mathbf{y}, \mathbf{y}(-\mathbf{1}))$ & 0.64 & 0.59 & 0.54 \\
& $(4.39)$ & $(4.53)$ & $(4.35)$ \\
$\rho(\mathbf{D Y}, \mathbf{D Y}(-\mathbf{1}))$ & 0.24 & 0.18 & 0.15 \\
& $(8.92)$ & $(8.14)$ & $(8.64)$ \\
$\rho(\mathbf{y}, \mathbf{n x} / \mathbf{y})$ & -0.13 & -0.15 & 0.03 \\
& $(7.03)$ & $(7.63)$ & $(4.89)$ \\
$\rho(\mathbf{y}, \mathbf{c})$ & 0.88 & 0.88 & 0.80 \\
& $(3.02)$ & $(3.20)$ & $(3.17)$ \\
$\rho(\mathbf{y}, \mathbf{i})$ & 0.69 & 0.63 & 0.39 \\
$\mathbf{E}(\mathbf{D Y})$ & $(3.54)$ & $(4.55)$ & $(4.36)$ \\
& 2.38 & 2.47 & 0.70 \\
& $(0.35)$ & $(0.50)$ & $(0.55)$ \\
\hline & & &
\end{tabular}

Notes: GMM estimates of the moments for the data and for the model with standard errors in parentheses. All standard errors and the standard deviations are in percentage. The variable $z$ is the cyclical component of $\log (Z)$ using the HP filter (with a coefficient equal to 100), $\sigma(z)$ denotes the standard deviation of the series $z, \rho(y, z)$ is the correlation coefficient between output $y$ and the variable $z$, for $z=\{y, i, c, n x / y\}$, and $E(D Y)$ is the mean of the growth rate of output $D Y=\log \left(Y / Y_{-1}\right)$. 


\section{LIST OF WORKING PAPERS RELEASED BY CEPII}

An Exhaustive list is available on the website: Ilwww.cepii.fr.

No

Title

Authors

2013-02 Nonlinearity of the Inflation-output Trade-off and Time-Varying Price Rigidity

A. López-Villavicencio \& V. Migon

2013-01 The Solow Growth Model with Keynesian

R. Magnani Involuntary Unemployments

2012-38 Does Migration Foster Exports? An African

H. Ehrhart, M. Le Goff, Perspective

E. Rocher \& R. J. Singh

2012-37 The ECB Unconventional Monetary Policies: Have U. Szczerbowicz they Lowered Market Borrowing Costs for Banks and Governments?

2012-36 The Impact of Market Regulations on Intra-European Real Exchange Rages

A. Bénassy-Quéré \& D. Coulibaly

2012-35 Exchange Rate volatility, Financial Constraints and Trade: Empirical Evidence from Chinese Firms

2012-34 Multinational Retailers and Home Country Exports

2012-33 Food Prices and Inflation Targeting in Emerging Economies

M. Pourroy, B. Carton \& D. Coulibaly

2012-32 Fiscal Consolidations and Banking Stability

J. Cimadomo, S. Hauptmeier \& T. Zimmermann

2012-31 The Contribution of the Yen Appreciation since 2007 to the Japanese Economic Debacle

W. Thorbecke 
No

Title

Authors

2012-30 Are the Benefits of Exports Support Durable?

O. Cadot, A. M. Fernandes, J. Gourdon \& A. Mattoo

2012-29 Les dessous de la dette publique japonaise

E. Dourille-Feer

2012-28 Invoicing Currency, Firm Size, and Hedging

J. Martin \& I. Méjean

2012-27 Product Relatedness and Firm Exports in China

S. Poncet \&

F. Starosta de Waldemar

2012-26 Export Upgrading and Growth: the Prerequisite of Domestic Embeddedness

S. Poncet \& F. Starosta de Waldemar

2012-25 Time to Ship During Financial Crises

N. Berman, J. de Sousa P. Martin \& T. Mayer

2012-24 Foreign Ownership Wage Premium: Does financial Health Matter?

2012-23 Tax Reform and Coordination in a Currency Union

2012-22 The Unequal Effects of Financial Development on Firms’ Growth in India

M. Bas

B. Carton

M. Bas \& A. Berthou

2012-21 Pegging Emerging Currencies in the Face of Dollar Swings

V. Coudert, C. Couharde \& V. Mignon

2012-20 On the Links between Stock and Comodity Markets' Volatility

A. Creti, M. Joëts \& V. Mignon

2012-19 European Export Performance, Angela Cheptea

A. Cheptea, L. Fontagné \& S. Zignago

2012-18 The Few Leading the Many: Foreign Affiliates and Business Cycle Comovement

J. Kleinert, J. Martin \& F. Toubal

2012-17 Native Language, Spoken Language, Translation and Trade

J. Melitz \& F. Toubal 
2012-16 Assessing the Price-Raising Effect of Non-Tariff O.Cadot \& J.Gourdon Measures in Africa

2012-15 International Migration and Trade Agreements: the New Role of PTAs

G. Orefice

2012-14 Scanning the Ups and Downs of China's Trade Imbalances

2012-13 Revisiting the Theory of Optimum Currency Areas: Is the CFA Franc Zone Sustainable?

C. Couharde,

I. Coulibaly, D. Guerreiro \& V. Mignon

2012-12 Macroeconomic Transmission of Eurozone Shocks to B. Erten Emerging Economies

2012-11 The fiscal Impact of Immigration in France: a Generational Accounting Approach

X. Chojnicki

2012-10 MAcMap-HS6 2007, an Exhaustive and Consistent Measure of Applied Protection in 2007

H. Guimbard, S. Jean, M. Mimouni \& X. Pichot

2012-09 Regional Integration and Natural Resources: Who Benefits? Evidence from MENA

C. Carrère, J. Gourdon \& M. Olarreaga

2012-08 A Foreign Direct Investment Database for Global CGE Models

C. Gouël, H. Guimbard \& D. Laborde

2012-07 On Currency Misalignments within the Euro Area

2012-06 How Frequently Firms Export? Evidence from France

2012-05 Fiscal Sustainability in the Presence of Systemic Banks: the Case of EU Countries

V. Coudert, C. Couharde \& V. Mignon

G. Békés, L. Fontagné, B. Muraközy \& V. Vicard

A. Bénassy-Quéré \& G. Roussellet

J. Martin \& I. Méjean

2012-04 Low-Wage Countries' Competition, Reallocation across Firms and the Quality Content of Exports 
No

Title

Authors

2012-03 The Great Shift: Macroeconomic Projections for the World Economy at the 2050 Horizon

J. Fouré,

A. Bénassy-Quéré \& L. Fontagné

2012-02 The Discriminatory Effect of Domestic Regulations

M. Crozet, E. Milet on International Services Trade: Evidence from Firm\& D. Mirza Level Data

2012-01 Optimal food price stabilization in a small open developing country

C. Gouël \& S. Jean 
Organisme public d'étude et de recherche en économie internationale, le CEPII est placé auprès du Centre d'Analyse Stratégique. Son programme de travail est fixé par un conseil composé de responsables de l'administration et de personnalités issues des entreprises, des organisations syndicales et de l’Université.

Les documents de travail du CEPII mettent à disposition du public professionnel des travaux effectués au CEPII, dans leur phase d'élaboration et de discussion avant publication définitive. Les documents de travail sont publiés sous la responsabilité de la direction du CEPII et n'engagent ni le conseil du Centre, ni le Centre d'Analyse Stratégique. Les opinions qui y sont exprimées sont celles des auteurs.

Les documents de travail du CEPII sont disponibles sur le site : http//www.cepii.fr. 